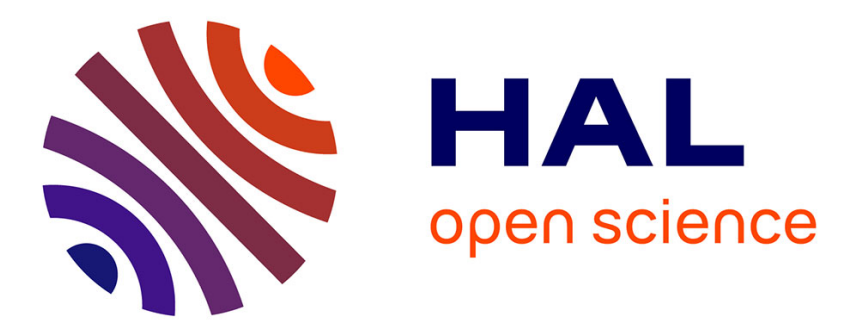

\title{
Modelling the impact of non-equilibrium discharges on reactive mixtures for simulations of plasma-assisted ignition in turbulent flows
}

Maria Castela, Benoît Fiorina, Axel Coussement, Olivier Gicquel, Nasser Darabiha, Christophe O. Laux

\section{To cite this version:}

Maria Castela, Benoît Fiorina, Axel Coussement, Olivier Gicquel, Nasser Darabiha, et al.. Modelling the impact of non-equilibrium discharges on reactive mixtures for simulations of plasma-assisted ignition in turbulent flows. Combustion and Flame, 2016, 166, pp.133-147. 10.1016/j.combustflame.2016.01.009 . hal-01513660

\author{
HAL Id: hal-01513660 \\ https://hal.science/hal-01513660
}

Submitted on 11 Mar 2020

HAL is a multi-disciplinary open access archive for the deposit and dissemination of scientific research documents, whether they are published or not. The documents may come from teaching and research institutions in France or abroad, or from public or private research centers.
L'archive ouverte pluridisciplinaire HAL, est destinée au dépôt et à la diffusion de documents scientifiques de niveau recherche, publiés ou non, émanant des établissements d'enseignement et de recherche français ou étrangers, des laboratoires publics ou privés. 


\title{
Modelling the impact of non-equilibrium discharges on reactive mixtures for simulations of plasma-assisted ignition in turbulent flows
}

\author{
Maria Castela $^{a}$, Benoît Fiorina ${ }^{a}$, Axel Coussement ${ }^{a, b}$, Olivier Gicquel ${ }^{a}$, Nasser Darabiha ${ }^{a}$, \\ Christophe O. Laux ${ }^{\mathrm{a}}$ \\ a Laboratoire EM2C, CNRS, Centrale Supélec, Université Paris-Saclay, Grande Voie des Vignes, 92295 Châtenay-Malabry Cedex, France \\ ${ }^{\mathrm{b}}$ Université Libre de Bruxelles, Ecole Polytechnique de Bruxelles, Aero-Thermo-Mechanics Laboratory, Bruxelles, Belgium
}

\begin{abstract}
A B S T R A C T
This article presents a model to describe the effects of non-equilibrium plasma discharges on gas temperature and species concentration, in the set of equations governing the combustion phenomena. Based on the results reported in the literature, the model is constructed by analysing the channels through which the electric energy is deposited. The two main channels by which the electrons produced during the discharge impact the flow are considered: (1) the excitation and the subsequent relaxation of electronic states of nitrogen molecules which leads to an ultrafast increase of gas temperature and species dissociation within the discharge characteristic time; and (2) the excitation and relaxation of vibrational states of nitrogen molecules which causes a much slower gas heating. The model is fully coupled with multi-dimensional flow balance equations with detailed transport coefficients and detailed combustion chemical kinetic mechanisms. This high level of NRP discharge modelling allows computing high Reynolds flows by means of Direct Numerical Simulations and, therefore, a better understanding of plasma-assisted ignition phenomena in practical configurations. A sequence of discharge pulses in air and methane-air mixture in quiescent and turbulent flow configurations are studied with this model. The results show the minor impact of the vibrational energy on mixture ignition and how the increase of the turbulence spreads this vibrational energy and intermediate combustion species around the discharge zone, minimizing the cumulative effect of multiple pulses. In contrast, the production of $\mathrm{O}$ atoms during the discharge has a strong impact on the ignition delays and ignition energies (number of discharge pulses). The results also underscore the impact of the initial turbulent flow Reynolds number and the spatial distribution of turbulent eddies, relative to the discharge channel, on the number of pulses needed to ignite the mixture.
\end{abstract}

\section{Introduction}

New combustion technologies to reduce pollutants emissions rely on premixed or partially premixed lean combustion regimes (e.g. MILD combustion, Homogeneous Charged Compression Ignition, Exhaust Gas Recirculation). However, due to low gas temperatures, the application of these new technologies to industrial systems is limited by the difficulty to control ignition and flame stabilization over a wide range of operational conditions. Non-equilibrium plasmas produce highly reactive radicals, mostly $O$ radicals in very short characteristic time scales, even at low mixture temperatures, and enhance combustion processes. The introduction of non-equilibrium plasmas in new technologies is therefore a promising solution to reduce ignition delays and extend the flame stability domain. For instance, the beneficial effects of using non-equilibrium plasmas on premixed swirled burners, representative of aeronautical combustors, were recently observed in Barbosa et al. [1]. Several laboratory scale experimental studies [2-7], have shown that, among non-equilibrium plasmas, those produced by Nanosecond Repetitively Pulsed (NRP) discharges are an energy-efficient way to initiate and control combustion processes particularly when conventional ignition systems (spark ignition) are rather ineffective or too energy costly [7-9]. Mixture ignition and flame stabilization inside a supersonic combustion chamber is particularly difficult at high Mach numbers. Experimental results presented in $[10,11]$ showed that the injection of non-equilibrium plasmas, produced with relatively small electric power, was very effective for flame stabilization under supersonic flow conditions, even at low static reactants temperature. More recent experimental studies have also shown the energy-efficiency of this kind of non-equilibrium plasmas produced by NRP 
discharges, on enhancing combustion processes [2,12,13]. The electric discharge energy is spent on ionization, excitation and dissociation of molecules, rather than just on a gas temperature increase [14-18]. Indeed, experiments and simulations in air at reduced electric fields $E / N>100 \mathrm{Td}\left(1 \mathrm{Td}=10^{-17} \mathrm{~V} \mathrm{~cm}{ }^{2}\right)$ have shown that, during NRP discharges, $\mathrm{N}_{2}$ and $\mathrm{O}_{2}$ molecules are excited to vibrational and electronic states [16,19-23], usually not in thermal equilibrium with the translational mode. The relaxation of these excited molecules by collisional quenching reactions with molecules can result in an ultrafast (time scales of nanoseconds) increase of radicals and gas temperature inside the discharge channel. In typical conditions, up to $50 \%$ of molecular oxygen can be dissociated in the inter-electrode region [18,22]. Hydroxyl radical is also formed along with hydrogen atoms when NRP discharges are applied to hydrocarbon-air mixtures, as discussed in $[23,24]$. Such high concentration of radicals has a positive effect on both ignition phenomena and flame stabilization [2,5,6,25-30].

The modelling of ignition by conventional spark (thermal plasmas) has been largely investigated in [31-33]. In these works, 2D numerical simulations in quiescent flow conditions with detailed chemistry, including ionization processes, were used to study the early development of the flame kernel and the fluid motion induced by spark discharges. 3-D DNS with simplified chemistry have been then performed to study the impact of different turbulence intensities on spark ignition in inhomogeneous mixtures [34]. However, few studies [28,35] have been pursued on the multi-dimensional modelling of ignition by NRP discharges. The phenomena occurring in NRP discharge-assisted combustion are still poorly understood, especially the gas dynamics and the thermochemical coupling between the discharge and the reactive flow. Some numerical simulations have recently been conducted to study the impact of NRP discharges on the flame and mixture ignition. Coupled plasma and combustion kinetic mechanisms have been used for that purpose. As an example, [28] simulated the plasma-assisted stabilization of a laminar premixed methane/air flame. Numerical investigations of $\mathrm{H}_{2}$ /air mixture ignition by NRP discharges in quiescent conditions were performed in [23,35].

The numerical studies presented in the literature are limited to $1-\mathrm{D}$ and 2-D simulations in quiescent flow conditions. The problem complexity increases in practical configurations as the ignition phenomena are also controlled by the flow and mixing field characteristics in and around the discharge channel. Furthermore, in NRP discharges, mixture ignition occurs due to the cumulative effect of successive pulses and not due to a single pulse energy addition, as in conventional spark ignition. The radicals formed by each pulse will enhance chain-branching reactions, increasing the local concentration of intermediate combustion species and, therefore, the mixture reactivity pulse after pulse. After a given number of pulses, the mixture ignites and a self-sustained flame kernel is developed. In turbulent flows, the high-temperature and highlyreactive kernel formed by each pulse may be stretched and convected away from the discharge zone before the next pulse, yielding a non-uniform distribution of temperature and concentration of radicals inside the discharge zone at the beginning of the following pulse. Depending on the characteristic time and length scales of turbulence and on the pulse repetition frequency, the cumulative effect of repetitively pulsed discharges may be minimized and, therefore, the number of pulses needed to ignite the mixture, as well as the ignition delay, may significantly increase.

Direct Numerical Simulations (DNS) is a powerful research tool to understand these turbulence/plasma-assisted ignition interactions. However, the computational cost of fully coupled nonequilibrium plasma and combustion detailed chemistry and high Reynolds flow simulations is prohibitive. In addition, the uncertainties associated to the coupling of these chemical models are still high.
The aim of the present paper is to provide a general phenomenological model for NRP discharges-assisted ignition, capable of taking into account the effects of non-equilibrium plasmas on the gas temperature and species concentration in the set of multicomponent reactive flow balance equations [36] governing the combustion phenomena. The model described next, is a high level modelling of non-equilibrium plasmas that avoids including detailed non-equilibrium plasma kinetics and, therefore, reduces the computational costs of high Reynolds flows DNS computations. Yet, it captures the main channels and their characteristic time scales through which the electric energy of the discharge is deposited into the flow. Nevertheless, detailed chemical kinetic model for hydrocarbons-air mixtures is considered, as well as multi-species transport model to capture the transient characteristics of NRP discharges-assisted ignition.

In the following sections the set of conservative equations of reactive systems in thermal equilibrium is briefly described. These conservative equations are then modified according to the proposed phenomenological NRP discharge model. The general model closure is presented and an analytical closure is proposed. Finally, numerical results of NRP discharges-assisted ignition are analysed for lean methane-air mixtures in quiescent and turbulent flow conditions.

\section{Governing equations for plasma-assisted combustion}

\subsection{Reactive flow equations without plasma}

The conservation equations for multicomponent reacting systems, where $N_{s p}$ species are in thermal equilibrium, can be written as follows:

$$
\begin{aligned}
& \frac{\partial \rho}{\partial t}+\frac{\partial\left(\rho u_{i}\right)}{\partial x_{i}}=0 \\
& \frac{\partial\left(\rho u_{j}\right)}{\partial t}+\frac{\partial\left(\rho u_{i} u_{j}\right)}{\partial x_{i}}=-\frac{\partial p}{\partial x_{j}}+\frac{\partial \tau_{i j}}{\partial x_{i}} \\
& \frac{\partial(\rho e)}{\partial t}+\frac{\partial\left(\rho u_{i} e\right)}{\partial x_{i}}=-\frac{\partial q_{i}}{\partial x_{i}}+\frac{\partial\left(\sigma_{i j} u_{i}\right)}{\partial x_{i}} \\
& \frac{\partial\left(\rho Y_{k}\right)}{\partial t}+\frac{\partial\left(\rho u_{i} Y_{k}\right)}{\partial x_{i}}=-\frac{\partial\left(\rho V_{k, i} Y_{k}\right)}{\partial x_{i}}+W_{k} \dot{\omega}_{k}^{c}
\end{aligned}
$$

where $\rho$ is the density, $u_{i}$ the velocity component in $x_{i}$ spatial direction, $p$ the pressure and $\tau_{i j}$ the viscous tensor. In Eq. (3), e refers to the gas total energy per unit mass defined as the sum of kinetic, thermal and chemical energies as follows:

$e=\frac{1}{2} u_{i} u_{i}+\sum_{k=1}^{N_{s p}}\left(e_{s k}+\Delta h_{f, k}^{o}\right) Y_{k}$

where $e_{s k}$ and $\Delta h_{f, k}^{o}$ are the sensible energy and enthalpy of formation of the $k$ th species, respectively. $Y_{k}$ and $W_{k}$ are the mass fraction and molar mass of the $k$ th species, respectively. In Eq. (4) the diffusion velocity of the $k$ th species, $V_{k, i}$, is computed assuming complex mixture average transport phenomena as in [37]. $\dot{\omega}_{k}^{c}$, the molar production rate of the $k$ th species due to combustion reactions, reads:

$$
\dot{\omega}_{k}^{c}=\sum_{i=1}^{I}\left(v_{k i}^{\prime \prime}-v_{k i}^{\prime}\right) \mathcal{Q}_{i}
$$

with

$$
\mathcal{Q}_{i}=K_{f i} \prod_{j=1}^{N_{s p}}\left[X_{j}\right]^{v_{j i}^{\prime}}-K_{r i} \prod_{j=1}^{N_{s p}}\left[X_{j}\right]^{v_{j i}^{\prime \prime}}
$$

where $\mathcal{Q}_{i}$ is the rate of progress of the $i$ th reaction, $\left[X_{j}\right]$ is the molar concentration of the $j$ th species and $K_{f i}$ and $K_{r i}$ are the rate 


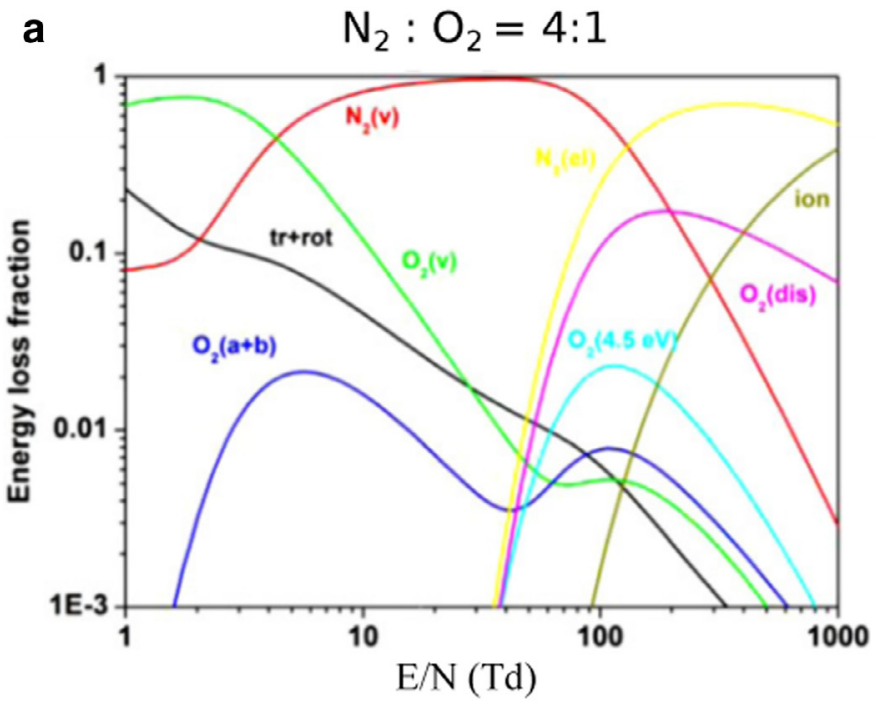

b $\quad \mathrm{N}_{2}: \mathrm{O}_{2}: \mathrm{CH}_{4}=8: 2: 1$

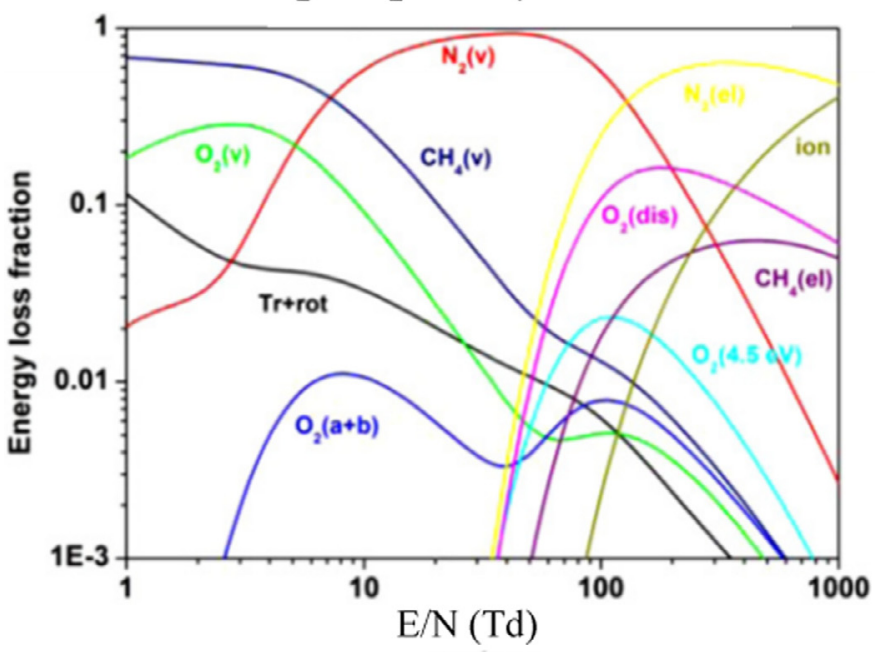

Fig. 1. Fractional power dissipated by electrons into the different molecular degrees of freedom as a function of $E / N$. (a) Air; and (b) methane-air stoichiometric mixture. Reproduced from Ref. [7].

constants for forward and reverse ith reaction following the Arrhenius law. $v_{k i}^{\prime}$ and $v_{k i}^{\prime \prime}$ are the stoichiometric coefficients of the $k$ th species appearing in the $i$ th reaction as a reactant and as a product, respectively.

\subsection{Phenomenological NRP discharge model}

NRP discharges are characterized by high-voltage pulses (from 5 to $20 \mathrm{kV}$ ) that last for a few nanoseconds and are repeated with frequencies of the order of tens of $\mathrm{kHz}$. During each high-voltage pulse, a strong electric field is formed increasing the kinetic energy of free electrons. This energy is then transferred to the surrounding heavy particles through a cascade of collisions, giving rise to excited particles, ions and atoms. The rate at which these collisional processes occurs depends on the parameter reduced electric field, $E / N$, defined as the ratio of the electric field to the total gas density, and on the mixture composition. Figures 1a and b show the distribution of the discharge energy into the different degrees of freedom of molecules as a function $E / N$, computed with detailed plasma kinetics. It is shown that, for values of $E / N$ in the range $100-400 \mathrm{Td}\left(1 \mathrm{Td}=10^{-17} \mathrm{~V} \mathrm{~cm}^{2}\right)$, the electrons accelerated by the electric field mainly produce electronically $\left(\mathrm{A}^{3} \sum_{u}^{+}\right.$, $\left.\mathrm{B}^{3} \Pi_{g}, \mathrm{C}^{3} \Pi_{u}, \mathrm{a}^{1} \Sigma_{u} \ldots\right)$ and vibrationally excited molecular nitrogen $[14,15]$. Additional energetic routes include processes such as electron-impact ionization, excitation of molecular oxygen, dissociation of molecular oxygen into ground $\left(\mathrm{O}^{3} \mathrm{P}\right)$ and excited $\left(\mathrm{O}^{1} \mathrm{D}\right)$ oxygen atoms, and dissociation of fuel molecules. Among these processes, those that consume most of the energy (about 90\% of the discharge energy) are the ones associated to the population of vibrational and electronic states of $\mathrm{N}_{2}$ molecules and the dissociation of $\mathrm{O}_{2}$ molecules by direct electron impact. This is the case in air (Fig. 1a), but also to a large extent in hydrocarbonair mixtures, since the mass fraction of hydrocarbons represents only a small fraction of the mixture composition (for instance, stoichiometric methane-air mixtures only contain $5.5 \%$ of methane in mass; Fig. 1b). For $E / N$ in this range, the impact of the discharge energy on the combustion processes is, therefore, ultimately associated to the effects of vibrationally excited $\mathrm{N}_{2}$ molecules, electronically excited $\mathrm{N}_{2}$ molecules and $\mathrm{O}$ atoms on the mixture thermodynamics. Several detailed plasma kinetic models are proposed in the literature $[19,21,29,30,38-42]$, to capture these nonequilibrium effects on the combustion processes. However, taking into account these detailed mechanisms in fully coupled, 2-D or 3-D, turbulent flow simulations requires considerable computational resources and, given the uncertainties on the rates, this approach may not provide more reliable results than the simpler approach proposed in this paper, capturing to first order all important plasma effects. Therefore, we have chosen to simplify the description of these kinetic processes using a phenomenological model based on the observation that, between 100 and $400 \mathrm{Td}$, the main effects of nanosecond pulsed discharges are the electronic and vibrational excitation of nitrogen molecules and the dissociation of $\mathrm{O}_{2}$ by direct electron impact. As it will be further discussed in Section 3.1, the relaxation of electronically excited $\mathrm{N}_{2}$ molecules translates into an ultrafast increase of the gas temperature and into the ultrafast dissociation of $\mathrm{O}_{2}$ molecules, whereas the relaxation of vibrationally excited $\mathrm{N}_{2}$ molecules translates into a slower heat release.

Figure 2 shows a schematic representation of the NRP discharge model developed in the present work. The impact of the discharge energy on the combustion governing equations is captured by additional species dissociation and heat sources. The model is based on three major assumptions:

1. The energy of the pulse is transferred to the gas within two characteristic time scales, hereinafter referred as $\tau_{\text {pulse }}$ and $\tau_{V T}$ :

- $\tau_{\text {pulse }}$ is the relaxation time of electronically excited $\mathrm{N}_{2}$ molecules (time scales of the order of nanoseconds);

- $\tau_{V T}$ is the vibrational-translational relaxation time of $\mathrm{N}_{2}$ molecules (time scales of the order of $1-100 \mu \mathrm{s}$ );

2. The fraction of the discharge energy deposited within $\tau_{\text {pulse }}$ leads to:

- an ultrafast dissociation of certain species and, therefore to the change of the chemical energy at a rate of $\dot{E}_{\text {chem }}^{p}$;

- an ultrafast increase of the gas temperature leading to an increase of the sensible energy at a rate of $\dot{E}_{\text {heat }}^{p}$;

- an ultrafast increase of the vibrational energy of the gas at a rate of $\dot{E}_{v i b}^{p}$

3. The vibrational energy subsequently relaxes into the translational modes, thus increasing the gas total energy within $\tau_{V T}$ at a rate $\dot{R}_{V T}^{p}$.

The rate of energy deposited by each pulse, $\dot{E}^{p}$, can therefore be written as the sum of three contributions:

$\dot{E}^{p}=\dot{E}_{\text {chem }}^{p}+\dot{E}_{\text {heat }}^{p}+\dot{E}_{v i b}^{p}$ 


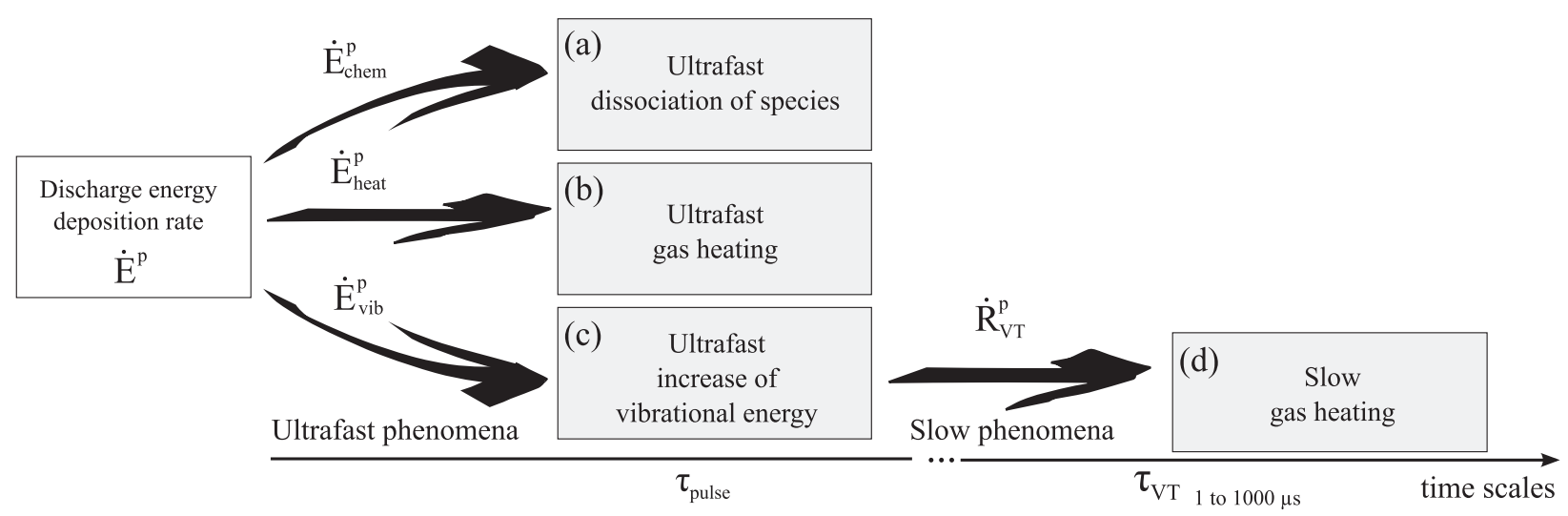

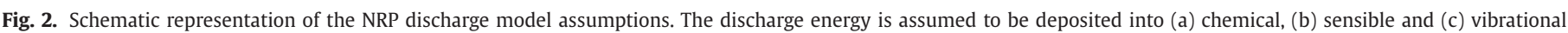

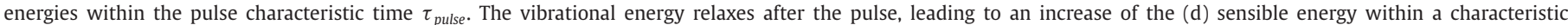
time $\tau_{V T}$.

where $\dot{E}_{\text {chem }}^{p}$ refers to the power going into ultrafast species dissociation, $\dot{E}_{\text {heat }}^{p}$ to ultrafast gas heating and $\dot{E}_{v i b}^{p}$ to the ultrafast increase of gas vibrational energy within the characteristic time $\tau_{\text {pulse }}$.

The contributions $\dot{E}_{\text {chem }}^{p}$ and $\dot{E}_{\text {heat }}^{p}$ are directly considered in the energy equation, Eq. (3), since the total energy, $e$, is defined as the sum of chemical, sensible and kinetic energies and since the characteristic time of these energy deposition rates, $\tau_{\text {pulse }}$, is extremely small compared to the flow and combustion characteristic times. On the other hand, the vibrational contribution $\dot{E}_{v i b}^{p}$ cannot be considered directly in this energy equation. It impacts the total energy only when it relaxes into gas heating. The vibrational levels of $\mathrm{N}_{2}$ molecules $[17,19,20]$ eventually reach equilibrium with the translational mode within a characteristic time $\tau_{V T}$. In [43], $\tau_{V T}$ of $\mathrm{N}_{2}$ molecules was studied for a wide range of gas temperatures and atomic and molecular oxygen concentrations. The results showed that $\tau_{V T}$ is very sensitive to the partial pressure of atomic oxygen and the mixture temperature. Therefore, in turbulent reactive flow conditions $\tau_{V T}$ may vary significantly depending on the local conditions of mixture temperature and species concentrations. If $\tau_{V T}$ is of the same order as the flow characteristic time, the vibrational energy is transported by the flow and heats up the gas mixture. An additional transport equation for the vibrational energy must be solved in the present formulation to close the relaxation rate of the vibrational energy, $\dot{R}_{V T}^{p}$.

Accordingly, the proposed set of conservation equations to model NRP discharges in reactive mixtures is as follows:

$\frac{\partial \rho}{\partial t}+\frac{\partial\left(\rho u_{i}\right)}{\partial x_{i}}=0$

$\frac{\partial\left(\rho u_{j}\right)}{\partial t}+\frac{\partial\left(\rho u_{i} u_{j}\right)}{\partial x_{i}}=-\frac{\partial p}{\partial x_{j}}+\frac{\partial \tau_{i j}}{\partial x_{i}}$

$\frac{\partial(\rho e)}{\partial t}+\frac{\partial\left(\rho u_{i} e\right)}{\partial x_{i}}=-\frac{\partial q_{i}}{\partial x_{i}}+\frac{\partial\left(\sigma_{i j} u_{i}\right)}{\partial x_{i}}+\dot{E}_{c h e m}^{p}+\dot{E}_{\text {heat }}^{p}+\dot{R}_{V T}^{p}$

$\frac{\partial\left(\rho e_{v i b}\right)}{\partial t}+\frac{\partial\left(\rho u_{i} e_{v i b}\right)}{\partial x_{i}}=\frac{\partial}{\partial x_{i}}\left(\rho \mathcal{D} \frac{\partial e_{v i b}}{\partial x_{i}}\right)+\dot{E}_{v i b}^{p}-\dot{R}_{V T}^{p}$

$\frac{\partial\left(\rho Y_{k}\right)}{\partial t}+\frac{\partial\left(\rho u_{i} Y_{k}\right)}{\partial x_{i}}=-\frac{\partial\left(\rho V_{k, i} Y_{k}\right)}{\partial x_{i}}+W_{k} \dot{\omega}_{k}^{c}+W_{k} \dot{\omega}_{k}^{p}$

Eqs. (8)-(10) and (12) corresponds to Eqs. (1)-(4), with the plasma source terms added. Eq. (11) is the additional conservation equation for the vibrational energy $e_{v i b}$, carried by $\mathrm{N}_{2}$ molecules, and therefore $\mathcal{D}$ is the diffusion coefficient of $\mathrm{N}_{2}$. The term $\dot{R}_{V T}^{p}$ in both Eqs. (10) and (11) refers to the relaxation rate of vibrational energy into gas heating. In Eq. (12), $\dot{\omega}_{k}^{p}$ is the molar production rate associated with the ultrafast species dissociation by the plasma discharge. The models for $\dot{E}_{c h e m}^{p}, \dot{E}_{\text {heat }}^{p}, \dot{E}_{v i b}^{p}, \dot{R}_{V T}^{p}$ and $\dot{\omega}_{k}^{p}$ are discussed below.

\subsection{General description of the model}

Previous plasma-assisted ignition models solve

- Ultrafast species dissociation and temperature increase - models for $\dot{E}_{\text {heat }}^{p}, \dot{E}_{\text {chem }}^{p}$ and $\dot{\omega}_{k}^{p}$ :

The distribution of the discharge power $\dot{E}^{p}$ over $\dot{E}_{c h e m}^{p}$ and $\dot{E}_{\text {heat }}^{p}$ depends on the local species concentration $X_{k=1, \ldots, N_{s p}}$, temperature $T$, and pressure $p$ of the gas mixture prior to the pulse. $\dot{E}_{\text {chem }}^{p}$ and $\dot{E}_{\text {heat }}^{p}$ can be expressed as a function of $\dot{E}^{p}$ as follows:

$\dot{E}_{\text {heat }}^{p}=g_{\text {heat }}\left(X_{k=1, \ldots, N_{s p}}, T, p\right) \cdot \dot{E}^{p}$

$\dot{E}_{\text {chem }}^{p}=g_{\text {chem }}\left(X_{k=1, \ldots, N_{s p}}, T, p\right) \cdot \dot{E}^{p}$

where $g_{\text {heat }}$ and $\mathrm{g}_{\text {chem }}$ are the fractions of the discharge energy transferred into sensible and chemical energy, respectively. $\dot{E}_{\text {chem }}^{p}$ can also be expressed in terms of the rate of production of species $k, \dot{\omega}_{k}^{p}$, associated with the plasma reactions occurring during the pulse:

$\dot{E}_{\text {chem }}^{p}=\sum_{k=1}^{N s p} e_{k} \dot{\omega}_{k}^{p}$

where $e_{k}$ is the energy of species $k$. For each species $k, e_{k} \dot{\omega}_{k}^{p}$ corresponds to a fraction $g_{\text {chem }}^{k}$ of the discharge power and reads:

$e_{k} \dot{\omega}_{k}^{p}=g_{\text {chem }}^{k}\left(X_{k=1, . ., N_{s p}}, T, p\right) \cdot \dot{E}^{p}$

The rate of production of the $k$ th species during the pulse is then given by:

$\dot{\omega}_{k}^{p}=g_{\text {chem }}^{k}\left(X_{k=1, \ldots, N_{s p}}, T, p\right) \cdot \frac{\dot{E}^{p}}{e_{k}}$

- Vibrational energy increase and its relaxation - models for $\dot{E}_{v i b}^{p}$ and $\dot{R}_{V T}^{p}$ :

The rate of increase of vibrational energy, $\dot{E}_{v i b}^{p}$ is given by the fraction of the discharge power that is not transferred into $\dot{E}_{\text {heat }}^{p}$ and $\dot{E}_{\text {chem }}^{p}$ within $\tau_{\text {pulse }}$. From Eqs. (13) and (14), $\dot{E}_{v i b}^{p}$ is therefore expressed as:

$\dot{E}_{v i b}^{p}=\left[1-\left(g_{\text {heat }}+g_{\text {chem }}\right)\right] \cdot \dot{E}^{p}$ 


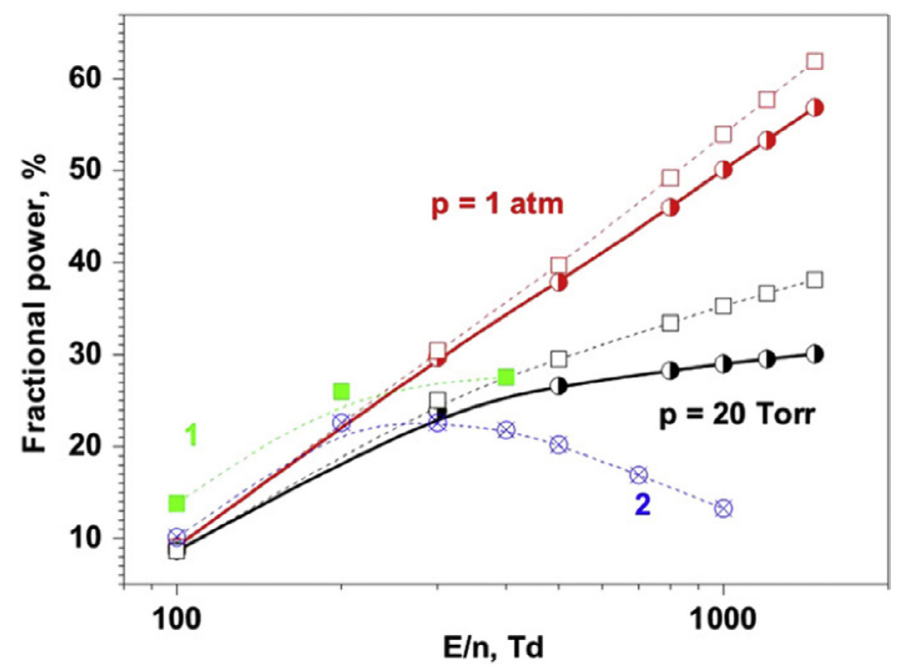

Fig. 3. The fraction of the total electron power transferred into heat in dry air at 20 Torr and $1 \mathrm{~atm}$ as a function of the reduced electric field at which the energy was deposited in a high-voltage nanosecond discharge. The calculations were carried out for $\mathrm{n}_{e f}=10^{15} \mathrm{~cm}^{-3}$ (solid curves) and $10^{14} \mathrm{~cm}^{-3}$ (dash curves) [20]. Curve 1 corresponds to calculations [17] and curve 2 corresponds to the calculations assuming that $28 \%$ of the energy spent on the excitation of electronic $\mathrm{N}_{2}$ and $\mathrm{O}_{2}$ states is quickly transferred into gas heating [19]. Reproduced from Ref. [20].

The relaxation rate of the vibrational energy into total energy, $\dot{R}_{V T}^{p}$, depends on the local species concentration, $X_{k=1, \ldots, N_{s p}}$, temperature $T$, and pressure $p$, and also on the local vibrational energy density $e_{v i b} . \dot{R}_{V T}^{p}$ can be expressed as follows:

$$
\dot{R}_{V T}^{p}=f\left(X_{i=1, \ldots, N_{s p}}, T, p, e_{v i b}\right)
$$

Once the functions $g_{\text {heat }}, g_{\text {chem }}^{k}, f$ and $\dot{E}^{p}$ are known, the terms $\dot{E}_{c h e m}^{p}, \dot{E}_{\text {heat }}^{p}$ and $\dot{R}_{V T}^{p}$ in the energy balance equation Eq. (10), as well as $\dot{\omega}_{k}^{p}$ in the species balance equation Eq. (12) and $\dot{E}_{v i b}^{p}$ in the vibrational energy balance equation Eq. (11) are closed. These functions can be deduced either from detailed plasma kinetic simulations or from semi-empirical models. In the following section, an analytical closure is proposed for the above general functions $g_{\text {heat }}, g_{\text {chem }}^{k}$ and $f$ based on the experimental and simulation values discussed in the literature.

\section{Model closure, solver and numerical set-up}

\subsection{Model closure}

The excited electronic states of $\mathrm{N}_{2}$ are rapidly quenched, mostly by a dissociative quenching reaction with $\mathrm{O}_{2}$, which takes place on time scales of the order of a few nanoseconds at atmospheric pressure. The mechanism is given by the following reactions:

$N_{2}(X)+e^{-} \rightarrow N_{2}\left(A, B, C, a^{\prime}, \ldots\right)+e^{-}$

$N_{2}\left(A, B, C, a^{\prime}, \ldots\right)+\mathrm{O}_{2} \rightarrow 2 O+N_{2}(X)+$ heat

where $N_{2}\left(A, B, C, a^{\prime}, \ldots\right)$ refers to the electronic excited states and $\mathrm{N}_{2}(X)$ the ground state of $\mathrm{N}_{2}$ molecules.

This two-step mechanism, which is an extension of the one proposed by [19] is known as the ultra-fast gas heating phenomenon. This two-step process results in ultrafast heating of the gas and ultrafast dissociation of $\mathrm{O}_{2}$. Figure 3 shows a comparative analysis of the numerical simulations performed by various authors of the fraction of the discharge power transferred into heat, in dry air at 20 Torr and $1 \mathrm{~atm}$, as a function of the reduced electric field [20]. It is shown that $10-30 \%$ of the electron energy is transferred into ultrafast gas heating for $100<E / N<400 \mathrm{Td}$ at atmospheric pressure. This is in agreement with the experimental observations of [22] who determined a fraction of about $20 \pm 5 \%$ in that same range of reduced electric fields.

The second important parameter is the fraction of energy going into $\mathrm{O}_{2}$ dissociation. The dissociation energy of $\mathrm{O}_{2}$ is about $5.2 \mathrm{eV}$, and the energies of the $\mathrm{N}_{2}(\mathrm{~B})$ and $\mathrm{N}_{2}(\mathrm{C})$ states, which are the main contributors to the ultrafast mechanism, are about $7.4 \mathrm{eV}$ and $11 \mathrm{eV}$, respectively. Thus, for reaction (21) with $\mathrm{N}_{2}$ (B), the ratio of energy going into dissociation $(5.2 \mathrm{eV})$ over the energy going into heating $(7.4-5.2=2.2 \mathrm{eV})$ is approximately 2.4 . For $\mathrm{N}_{2}(\mathrm{C})$, this ratio is about 0.9. We therefore expect that the overall ratio will lie between these two values, but closer to the high end of the range because of the higher population of $\mathrm{N}_{2}(\mathrm{~B})$. In the experiments of [22] and simulations of [44], this ratio was found to be about 1.75 (35 $\pm 5 \%$ into dissociation and $20 \pm 5 \%$ into heating), which is consistent with the foregoing analysis. Thus, we base our model on the experimental and simulation values of 35\% of energy going into ultrafast dissociation, and $20 \%$ into ultrafast heating. Finally, we consider that the balance of the discharge energy, about $45 \%$, is spent on the vibrational excitation of $\mathrm{N}_{2}$ by electron impact.

Following these values and the model presented in Section 2.2, in the present work we consider that:

- The ultrafast characteristic time defined in the model as $\tau_{\text {pulse }}$ is chosen to approximately represent the characteristic production time of $\mathrm{O}$ radicals $\approx 50 \mathrm{~ns}$, as observed in the experimental work of [22]. Its exact value is not critical, as it is much shorter than the characteristic scales of gas dynamics [45];

- Only the dissociation process $\mathrm{O}_{2} \rightarrow 20$ occurs within $\tau_{\text {pulse }}$. Therefore the species considered in Eq. (17) are only $\mathrm{O}_{2}$ molecules and $\mathrm{O}$ radicals. As the mass conservation of combustion species production is ensured by $\sum_{k=1}^{N s p} M_{k} \dot{\omega}_{k}^{c}=0$, the conservation of the mass of species involved in this plasma reaction implies:

$\dot{\omega}_{O_{2}}^{p}=-\frac{W_{O}}{W_{O 2}} \dot{\omega}_{O}^{p}$

and

$$
\dot{\omega}_{k}^{p}=0 \quad \text { if } \mathrm{k} \neq \mathrm{O}_{2}, \mathrm{O}
$$

- Following Eqs. (17) and (18) the discharge energy consumed in the dissociation process is written as:

$$
\begin{aligned}
\dot{E}_{\text {chem }}^{p} & =\left(g_{\text {chem }}^{O}+g_{\text {chem }}^{O_{2}}\right) \dot{E}^{p} \\
& =e_{0} \dot{\omega}_{\mathrm{O}}+e_{\mathrm{O}_{2}} \dot{\omega}_{\mathrm{O}_{2}}
\end{aligned}
$$

The reaction rate of $\mathrm{O}_{2}$ dissociation involved in plasma reactions depends on the available quantity of $\mathrm{O}_{2}$; therefore $g_{\text {chem }}^{\mathrm{O}}$ is assumed proportional to the ratio $\mathrm{Y}_{\mathrm{O}_{2}} / \mathrm{Y}_{\mathrm{O}_{2}}^{f}$ where $\mathrm{Y}_{\mathrm{O}_{2}}^{f}$ represents the mass fraction of $\mathrm{O}_{2}$ in the fresh mixture:

$g_{\text {chem }}^{0}=\eta \frac{Y_{\mathrm{O}_{2}}}{Y_{\mathrm{O}_{2}}^{f}}$

where $\eta$ is the fraction of the discharge power leading to $\mathrm{O}_{2}$ dissociation, with $\eta=0.35$ as justified above.

From Eq. (17) the molar production rate $\dot{\omega}_{O}^{p}$ can then be expressed by:

$\dot{\omega}_{O}^{p}=\eta \frac{Y_{O_{2}}}{Y_{O_{2}}^{f}} \frac{\dot{E}^{p}}{e_{O}}$

This means that when all $\mathrm{O}_{2}$ molecules are locally consumed, $\dot{\omega}_{O}^{p}$ will vanish. Introducing Eqs. (27) and (22) into Eq. (25) one obtains the expression for $\dot{E}_{\text {chem }}^{p}$ :

$\dot{E}_{\text {chem }}^{p}=\eta \frac{Y_{O 2}}{Y_{O 2}^{f}}\left(1-\frac{W_{O}}{W_{O 2}} \frac{e_{O_{2}}}{e_{O}}\right) \dot{E}^{p}$ 
Table 1

Vibrational constants $a$ and $b$ for $\mathrm{N}_{2}, \mathrm{O}_{2}$ and $\mathrm{O}$ used in Eq. (35).

\begin{tabular}{lcl}
\hline Colliding species & $\mathrm{a}_{k}$ & $b_{k}$ \\
\hline $\mathrm{N}_{2}$ & 221.0 & 0.029 \\
$\mathrm{O}_{2}$ & 229.0 & 0.0295 \\
$\mathrm{O}$ & 72.4 & 0.015 \\
\hline
\end{tabular}

- The sum of the power going into ultrafast dissociation $\left(\dot{E}_{c h e m}^{p}\right)$ and ultrafast heating $\left(\dot{E}_{\text {heat }}^{p}\right)$ is equal to the power going into the electronic excitation of $\mathrm{N}_{2}$. Thus it is proportional to $\dot{E}^{p}$ :

$\dot{E}_{\text {chem }}^{p}+\dot{E}_{\text {heat }}^{p}=\alpha \dot{E}^{p}$

and, in our model, we assume $\alpha=0.55$ (0.35 for ultrafast dissociation and 0.20 for ultrafast heating). Combining Eqs. (28) and (29), we have:

$\dot{E}_{\text {heat }}^{p}=\left[\alpha-\eta \frac{Y_{02}}{Y_{02}^{f}}\left(1-\frac{W_{O}}{W_{02}} \frac{e_{O_{2}}}{e_{0}}\right)\right] \dot{E}^{p}$

Therefore, the fraction $\dot{E}_{\text {heat }}^{p}$ increases when $\mathrm{Y}_{\mathrm{O}_{2}}$ decreases, and reaches $\alpha \dot{E}^{p}$ when $\mathrm{O}_{2}$ vanishes. This is physically reasonable because the relaxation of $\mathrm{N}_{2}^{*}$ will then occur by collisions with $\mathrm{N}_{2}$, which is still an ultrafast heating process with a characteristic time of 10-100 ns (see Tables 5 and 6 in [22]).

- The rate of vibrational energy increase, $\dot{E}_{v i b}$ is given by substituting Eq. (29) into Eq. (7):

$\dot{E}_{v i b}=(1-\alpha) \dot{E}^{p}$

- The vibrational-translational energy exchange rate, $\dot{R}_{V T}^{p}$ in Eqs. (10) and (11) is modelled considering the Landau-Teller harmonic oscillator approach:

$\dot{\mathrm{R}}_{V T}^{p}=\rho \frac{e_{v i b}-e_{v i b}^{e q}(T)}{\tau_{V T}}$

in which the equilibrium value of the vibrational energy at a given mixture temperature, $e_{v i b}^{e q}(T)$, is defined as:

$e_{v i b}^{e q}(T)=\frac{r \Theta_{1}}{e^{\Theta_{1} / T}-1}$

where $\Theta_{1}=3396 \mathrm{~K}$ is the vibrational temperature corresponding to the first quantum vibrational state of $\mathrm{N}_{2}$ and $r=R / W_{N_{2}}$, with $R$ the gas constant and $W_{N_{2}}$ the nitrogen molar mass. $\tau_{V T}$ is computed as a function of $\tau_{V T}^{k}$ given by the experimental correlation of [43]:

$\tau_{V T}=\left(\frac{1}{\tau_{V T}^{O}}+\frac{1}{\tau_{V T}^{O_{2}}}+\frac{1}{\tau_{V T}^{N_{2}}}\right)^{-1}$

$\tau_{V T}^{k}=c / p_{k} \exp \left[a_{k}\left(T^{-1 / 3}-b_{k}\right)-18.42\right]$

where $\tau_{V T}^{k}$ is the vibrational-translational relaxation time of $\mathrm{N}_{2}$ molecules by the $k$ th collisional species partner $\left(\mathrm{O}_{2}, \mathrm{O}\right.$ and $\left.\mathrm{N}_{2}\right)$. $c=1 \mathrm{~atm} s, p_{k}$ is the partial pressure of the $k$ th species and $\mathrm{a}_{k}$ and $\mathrm{b}_{k}$ are experimental constants depending on the $k$ th species (see Table 1).

\subsection{Temporal and spatial distribution model for $\dot{E}^{p}$}

This model is characterized by two semi-empirical parameters $\alpha$ and $\eta$ as well as by the temporal and spatial distribution function of the discharge energy deposition rate $\dot{E}^{p} . \dot{E}^{p}$ is applied at a given pulse frequency, $f$, to simulate a multi-pulse regime. The discharge energy per unit volume, referred hereinafter as $\sigma_{\text {pulse }}$, is
Pin-to-pin configuration

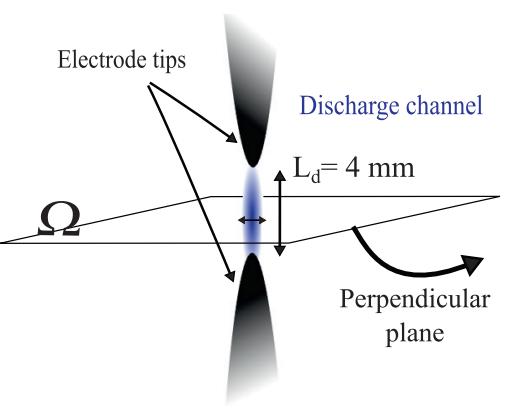

$D_{d}$ - Discharge channel diameter

$\mathrm{L}_{\mathrm{d}}$ - Discharge channel length

Fig. 4. Schematics of a pin-to-pin configuration of NRP discharges device. The 2-D computational domain is a plane perpendicular to the electrode tips.

assumed uniformly deposited within the characteristic time, $\tau_{\text {pulse }}$ and therefore $\dot{E}^{p}$ is modelled as follows:

$\dot{E}^{p}\left(t_{\text {per }}, x_{i}\right)= \begin{cases}\frac{\sigma_{\text {pulse }}}{\tau_{\text {pulse }}} \cdot \mathcal{F}(r) & \text { if } t_{\text {per }} \leq \tau_{\text {pulse }} \\ 0 & \text { if } t_{\text {per }}>\tau_{\text {pulse }}\end{cases}$

where $t_{p e r}$ refers to the time in the pulse referential (i.e. related to the beginning of each pulse, determined by the pulse repetition frequency $f$ ). The spatial function $\mathcal{F}(r)$ defines the region where the plasma discharge occurs. In the present study we consider a 2-D domain comprising the cross-section of an infinitely long cylindrical-shape discharge channel. The 2-D spatial function $\mathcal{F}(r)$ is, therefore, considered as follows:

$\mathcal{F}(r)=\operatorname{erfc}\left(\frac{r}{a}\right)^{b}$

where $r$ refers to the radial distance from the discharge axis and $a$ and $b$ are geometric parameters. These geometric parameters are computed so that the area defined by this function is equal to $\pi r_{d}^{2}$, with $r_{d}$ the discharge radius. The volume of the discharge is thus given by the equivalent $V=\pi r_{d}^{2} \times L_{d}$, with $L_{d}$ the discharge length. Therefore, the energy per unit volume deposited by each pulse reads:

$\sigma_{\text {pulse }}=\frac{E_{\text {pulse }}}{\pi r_{d}^{2} \times L_{d}}$

\subsection{Solver and numerical set-up}

The NRP discharges used in the present numerical simulations represents the ones characterized in the experimental work of [22]. The plasma discharge channel is cylindrical, with diameter $r_{d}=$ $225 \mu \mathrm{m}$ and height $L_{d}=4 \mathrm{~mm}$. Since $D_{d} / L_{d}<<1$, both gas temperature and species axial gradients are negligible compared to the radial gradients and therefore, a 2-D computational domain perpendicular to the electrode tips is considered, as shown in Fig. 4. A constant pulse energy density of $\sigma_{\text {pulse }}=1.1 \times 10^{6} \mathrm{~J} / \mathrm{m}^{3}$ is applied, which represents an energy per pulse of $700 \mu \mathrm{J}$ as in [22].

The model is implemented in a structured Direct Numerical Simulation solver - YWC - dedicated to compressible reactive flow simulations with detailed chemistry and multicomponent mixture averaged transport properties [37]. The spatial derivatives are computed with a 4 th order centred finite-difference scheme. An 8th order filtering scheme is used for stability purpose. The code is explicit in time using a 4th order Runge-Kutta method. To capture stiff pressure waves induced by each plasma discharge, 
Table 2

Parameters of the NRP assisted ignition model and flow characteristics used in the DNS test-cases.

\begin{tabular}{lllllc}
\hline Test-case & $\eta$ & $\alpha$ & Flow & $u^{\prime}(\mathrm{m} / \mathrm{s})$ & Nb discharges \\
\hline Air & 0.35 & 0.55 & Quiesc. & - & 10 \\
Air & 0.00 & 0.55 & Quiesc. & - & 10 \\
Methane-air & 0.35 & 0.55 & Quiesc. & - & 2 \\
Methane-air & 0.0 & 0.55 & Quiesc. & - & 4 \\
Methane-air & 0.35 & 0.55 & $\operatorname{Re}_{l t}=44$ & 2 & 2 \\
Methane-air & 0.35 & 0.55 & $\operatorname{Re}_{l t}=395$ & 6 & 3 to 4 \\
\hline
\end{tabular}

the hyper-viscosity technique developed in [46-48] is employed. The numerical configuration is shown in Fig. 4. Nonreflecting boundaries in $x$ and $y$ directions were used.

Table 2 summarizes the model parameters and flow characteristics of the test-cases studied in the present work, where the model closure presented in Sections 3.1 and 3.2 is applied. Three different applications of the model are shown:

1. NRP discharges in air;

2. NRP discharges in premixed methane-air quiescent flows;

3. NRP discharges in premixed methane-air turbulent flows.

A methane-air mixture characterized by an equivalence ratio of $\phi=0.8$ is used in all reactive flow simulations where the detailed mechanism from Lindstedt [49] comprising 29 species and 141 elementary reactions was considered. For all simulations, the initial pressure and gas temperature in the solution domain is uniform and equal to $1 \mathrm{~atm}$ and $300 \mathrm{~K}$, respectively. The pulse repetition frequency $f=10 \mathrm{kHz}$ is kept constant for all simulations. In turbulent studies, the initial homogeneous isotropic velocity fields are initialized using the Passot-Pouquet spectrum with a constant value of the most energetic scale, $l_{e}=6.25 \times 10^{-4} \mathrm{~m}$ and $u^{\prime}$ given in Table 2. The turbulent Reynolds number is defined as $\operatorname{Re}_{l t}=\frac{l_{t} \cdot u^{\prime}}{v}$, where $l_{t}$ is the integral length scale and $v$ is the air viscosity com- puted for the initial conditions of the simulations. The computations are performed on a $512 \times 512$ uniform 2-D mesh grid, with cell size of $10 \mu \mathrm{m}$. The computational domain is chosen so that the smallest scales of turbulence, given by the Kolmogorov scales, are resolved and so that the turbulent integral scales should be less than $1 / 4$ of the solution domain length to avoid the influence of boundary conditions. In the test-cases of $\operatorname{Re}_{l t}=44$ and $\mathrm{Re}_{l t}=$ 395, the Kolmogorov scales are $\eta=24.4 \mu \mathrm{m}$ and $\eta=14.1 \mu \mathrm{m}$, respectively, which correspond to at least 1.4 times the grid spacing $(10 \mu \mathrm{m})$. The integral length scales of $l_{t}=0.208 \mathrm{~mm}$ and $l_{t}=$ $1.23 \mathrm{~mm}$ require that the solution domain should be at least $4 \times$ $1.23 \mathrm{~mm}$, which is satisfied here by the computational domain size.

\subsection{Validation of the model}

A preliminary test-case is performed to validate the model behaviour during a single discharge pulse. For this, model results are compared with the experimental data of [22]. The initial conditions of gas temperature, pressure and $\mathrm{O}$ radicals concentration as well as the discharge energy $(700 \mu \mathrm{J} /$ pulse $)$ and radius $(r=225 \mu \mathrm{m})$ correspond to the experimental conditions in the steady pulsing regime. A constant value of the model parameter $\alpha=0.55$ is retained whereas two values of the model parameter $\eta$ ( 0 and 0.35$)$ are analysed in order to understand the impact of the early distribution of the discharge energy into $\dot{E}_{\text {chem }}^{p}$ and $\dot{E}_{\text {heat }}^{p}$.

Figure 5 shows the evolution of the gas temperature, pressure and $\mathrm{O}$ radicals concentration during the pulse. For the reference case, where $\eta$ is set to 0.35 (meaning that $35 \%$ of the pulse energy is routed to the dissociation of $\mathrm{O}_{2}$ ), the pressure rises up to $2 \mathrm{~atm}$, the temperature increases by about $1100 \mathrm{~K}$ and the $\mathrm{O}$ radical concentration rises from 3 up to $9 \times 10^{17}$ particles $/ \mathrm{cm}^{3}$, as expected. The results are in good agreement with the experimental values apart from the characteristic rise time of the gas temperature that was considered here equal to $\tau_{\text {pulse }}=50$ ns versus the experimental value of 25 ns. This value is a good compromise
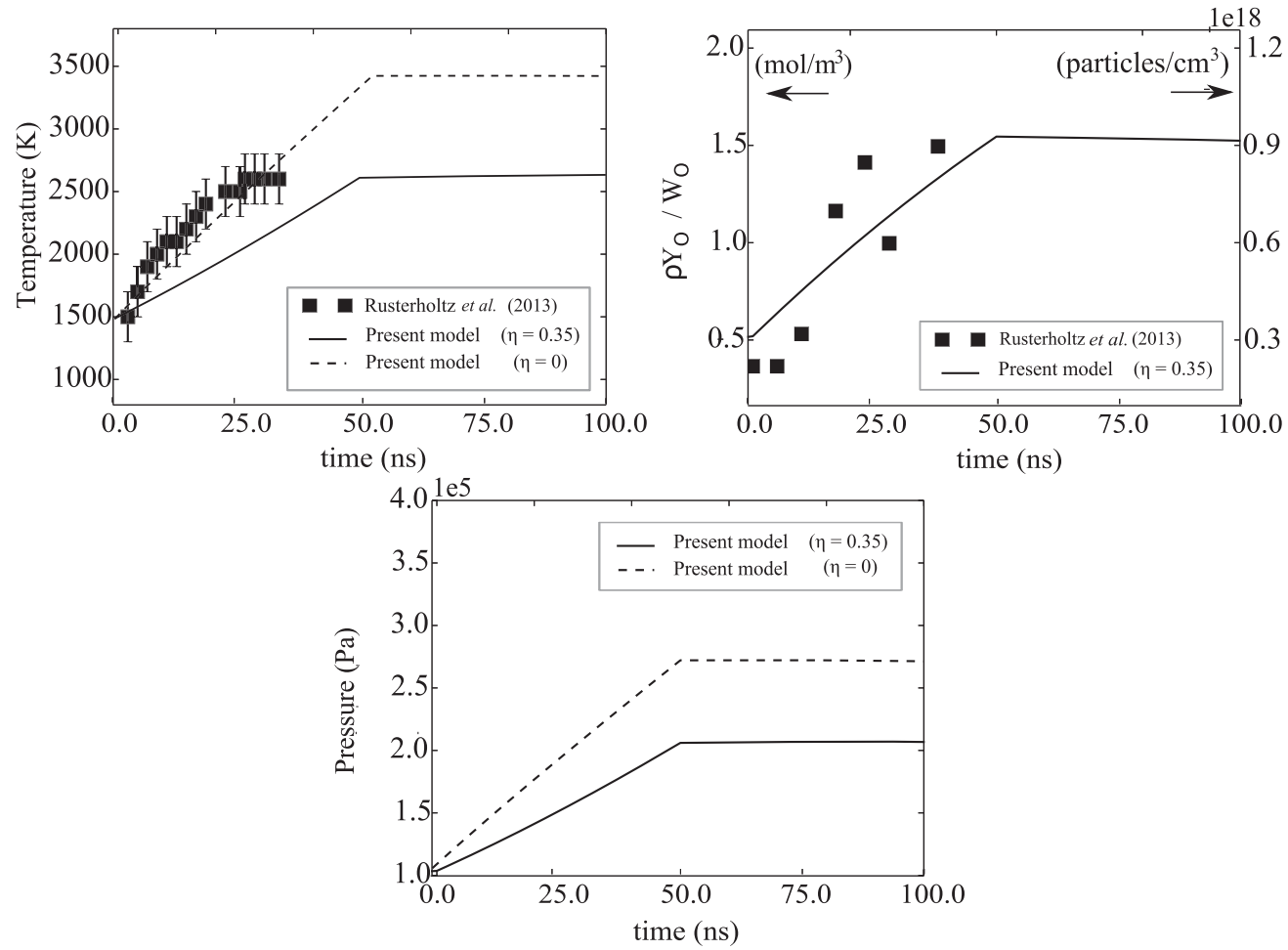

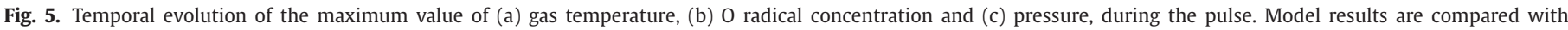
the experimental results obtained in [22]. 
a

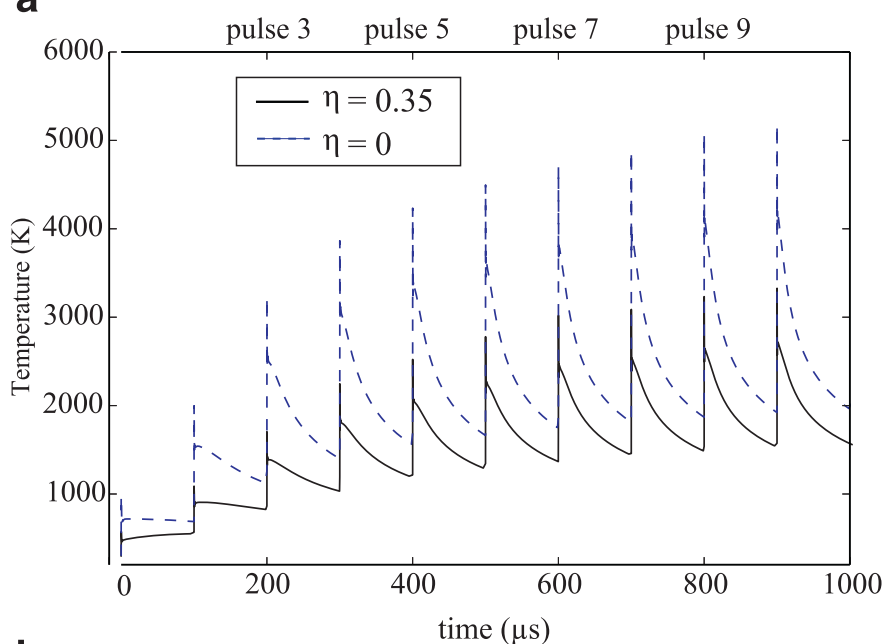

b

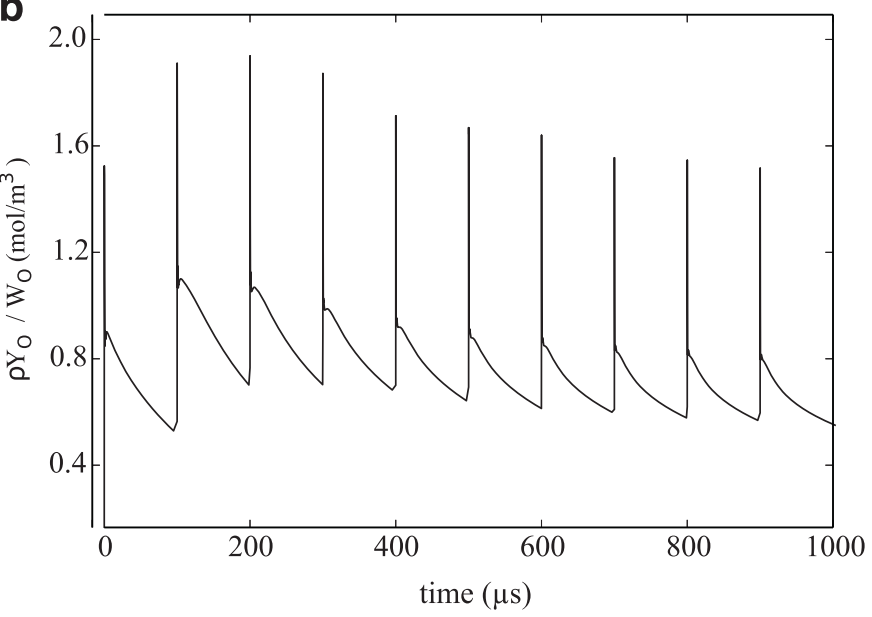

Fig. 6. Temporal evolution of (a) the gas temperature and (b) the oxygen concentration at the centre of the discharge channel in a sequence of 10 pulses in air. The following parameter values were used: pulse repetition frequency $f=10 \mathrm{kHz}$, energy density per pulse $\sigma_{\text {pulse }}=1.1 \times 10^{6} \mathrm{~J} / \mathrm{m}^{3}$ and model parameters: $\alpha=0.55$ and two values of $\eta$ : 0.35 and 0 .

regarding the characteristic rise time of $O$ radicals density and since we are only considering a single time-step $\tau_{\text {pulse }}$ to capture all the characteristic times of the plasma reactions that lead to both the gas temperature increase and the $\mathrm{O}_{2}$ dissociation. We emphasize that, at the end of $\tau_{\text {pulse }}=50 \mathrm{~ns}$, both values of the gas temperature and of the $\mathrm{O}$ radicals concentration agree well with experimental data. When $\eta$ is set to 0 , meaning that all the $55 \%$ of the discharge energy is transferred directly into $\dot{E}_{\text {heat }}^{p}$ (and $\dot{E}_{\text {chem }}^{p}$ $=0$ ), the gas pressure rises up to $2.8 \mathrm{~atm}$ and the temperature increases by about $1900 \mathrm{~K}$, overestimating the experimental results of [22].

\section{Results and discussion}

\subsection{NRP discharges in air}

A sequence of NRP discharges are applied in air with frequency, $f=10 \mathrm{kHz}$, energy density per pulse $\sigma_{\text {pulse }}=1.1 \times 10^{6} \mathrm{~J} / \mathrm{m}^{3}$ and discharge radius, $r=225 \mu \mathrm{m}$, as discussed in Section 3.3. The values of the model parameters are $\alpha=0.55$ and $\eta=0.35$.

Figure 6 shows the temporal evolution of the gas temperature and oxygen molar concentration at the centre of the discharge zone for this sequence of pulses. During each pulse, the results a
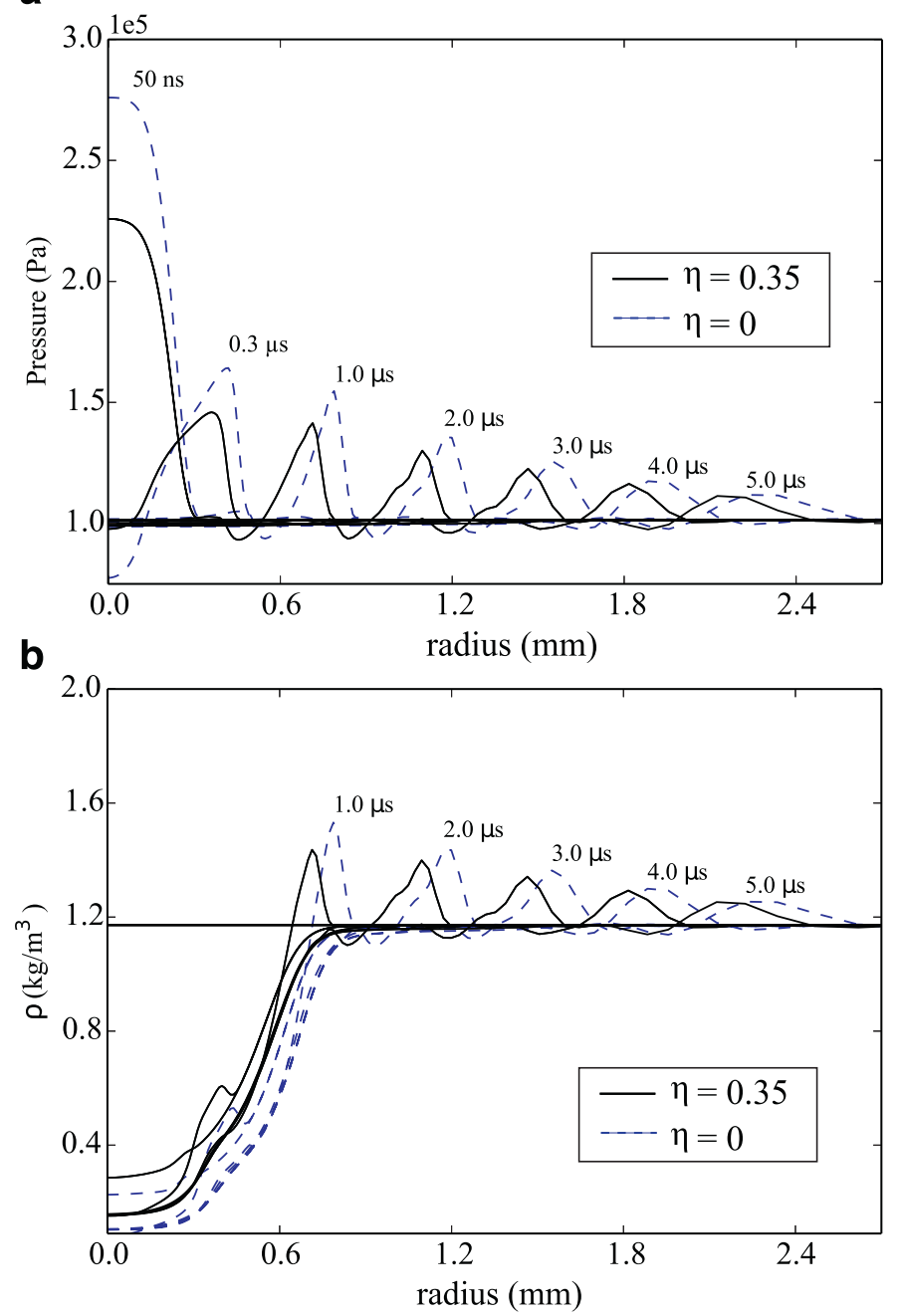

Fig. 7. Time series of the (a) pressure wave and (b) the gas density radial profiles after the 5th pulse. Two values of the model parameter $\eta$ are considered: $\eta=0$ and $\eta=0.35$.

show an ultrafast increase of the gas temperature by about 1000 $2000 \mathrm{~K}$. Then the temperature progressively decreases between pulses due to the gas expansion and diffusion effects. At the end of each period, the value of the gas temperature is higher than that of the previous period. Nevertheless, this minimum temperature reaches a quasi-stationary value of about $1600 \mathrm{~K}$ after height pulses when diffusive fluxes are balanced with the heat released by the discharge. This temperature value is in good agreement with the one observed in the stationary regime in [22]. The evolution of the $\mathrm{O}$ radicals concentration for the same sequence of NRP discharges shows that during each pulse, $\mathrm{O}$ radicals rapidly increase and then decrease due to gas expansion, diffusion and to the recombination of $\mathrm{O}$ radicals into $\mathrm{O}_{2}$ molecules. The minimum and the maximum values of the $\mathrm{O}$ radicals concentration are close to the ones observed in the experimental work of [22] in the stationary regime. When the $\eta$ is set to 0 , the simulation results show a much significant increase of the gas temperature during the pulse by about $3000 \mathrm{~K}$, overestimating the experimental results of [22].

Due to the fast energy deposition (within $\tau_{\text {pulse }}=50 \mathrm{~ns}$ ), compressible effects occur at each discharge pulse, as shown experimentally by [50]. For a better understanding of the gas dynamics effects occurring at each single pulse, Fig. 7 shows the temporal evolution of the gas pressure and density radial profiles following the 5 th discharge of this sequence of pulses. Two values of 


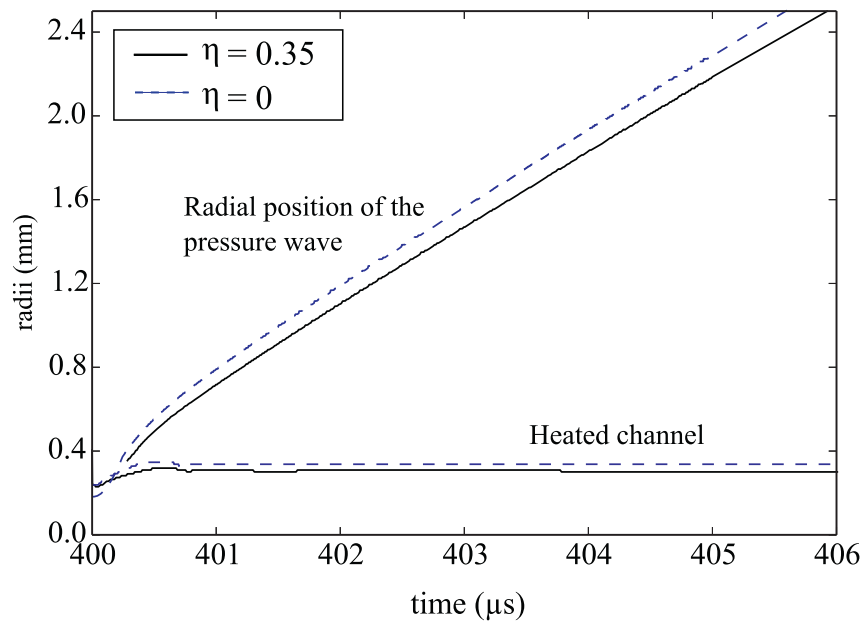

Fig. 8. Temporal evolution of the radial position of the pressure wave and the heated channel after the 5 th pulse. Two values of the model parameter $\eta$ are considered: $\eta=0.35$ and 0 .

the model parameter $\eta(0$ and 0.35$)$ are analysed. Figure 7 a shows that, after the fast increase of the pressure, the gas expands and an initial shock wave separates at approximately $t=0.25 \mu \mathrm{s}$ and propagates outwards through the surrounding air. As the external source of energy ceases after the pulse and since the energy must be spread over an ever-increasing radius (2-D computations), the shock strength diminishes due to both the expansion and viscous dissipation. The shock wave eventually decays into a sound wave. As can be inferred from the slope of the temporal evolution of the pressure wave radius shown in Fig. 8, when the shock wave leaves the discharge zone, its Mach number is slightly larger than 1 and then decreases towards unity. When $\eta=0$, the pressure wave separates faster due to its higher initial velocity. Figure 7a also shows that the pressure waves are rapidly attenuated right after leaving the discharge zone and at $r=2.4 \mathrm{~mm}$ their amplitude is of the order of $1.2 \mathrm{~atm}$ for both values of $\eta$. Figure $7 \mathrm{~b}$ shows that the separation time of the density wave is about $t=1 \mu \mathrm{s}$, this characteristic time depends on the extent of the heated channel and therefore on the number of pulses previously applied and on the amount of the discharge energy going into the ultrafast increase of gas temperature during the discharge. Due to these pressure waves created by the plasma discharge, part of the deposited energy leaves the discharge zone as acoustic energy. For $\eta=0.35$ about $10 \%$ of the pulse energy is converted into acoustic energy, whereas for $\eta=0$ this value increases to about $20 \%$. It is, therefore, interesting to emphasize that by transferring part of the pulse energy into chemical energy, the losses by acoustic energy runaway from the discharge zone are reduced.

The early dissociation of $\mathrm{O}_{2}$ also impacts the relaxation rate of gas vibrational energy. Indeed, as expected from the experimental results of [43], through the empirical correlation of the vibrational energy relaxation time given in Eq. (35) the rate of V-T transfer is greatly increased in the presence of $\mathrm{O}$ atoms. As shown in Fig. 9 when $\eta=0.35$, after the $3 r d$ pulse, most of the vibrational energy deposited during each pulse is relaxed before the next one. On the other hand, for $\eta=0$, the relaxation of vibrational energy is much slower than the pulse period. It should be noted that the V-T rate of Popov [21]: $\tau_{V T}=\frac{1}{p_{0}} k_{\beta} T / k_{V T}$, with $k_{\beta}$ the Boltzmann constant and $k_{V T}=4.5 \times 10^{-15}\left(\frac{T}{300}\right)^{2.1}$, are faster than the ones used here (about 220 times faster at $300 \mathrm{~K}$ and $10-20$ faster between $1000 \mathrm{~K}$ and $2000 \mathrm{~K}$ ). Therefore, the vibrational energy may relax even faster than predicted here. This will be investigated in future work.

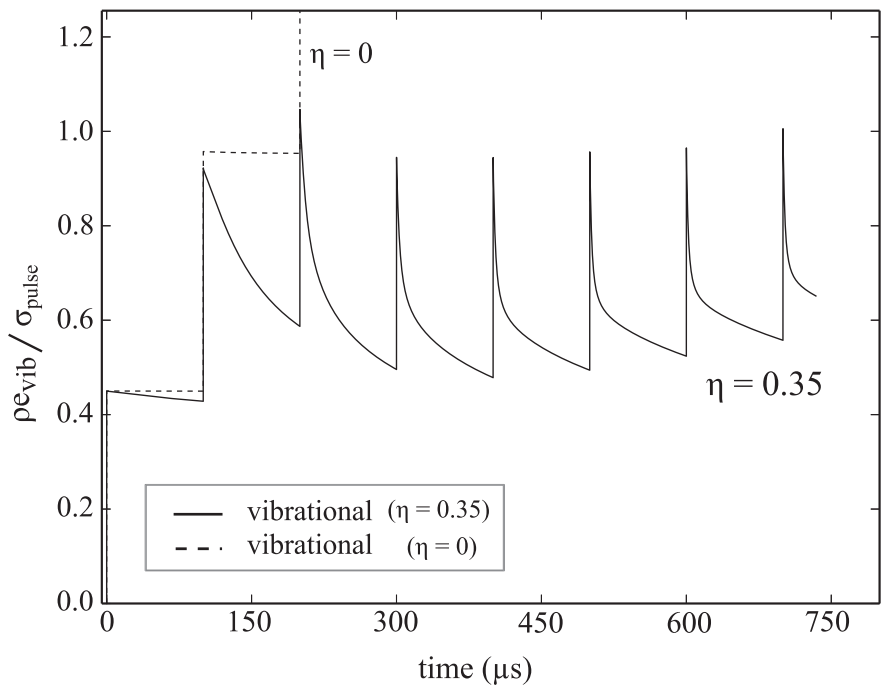

Fig. 9. Temporal evolution of gas vibrational energy in a sequence of NRP discharges in air, two values of the model parameter $\eta$ are considered.

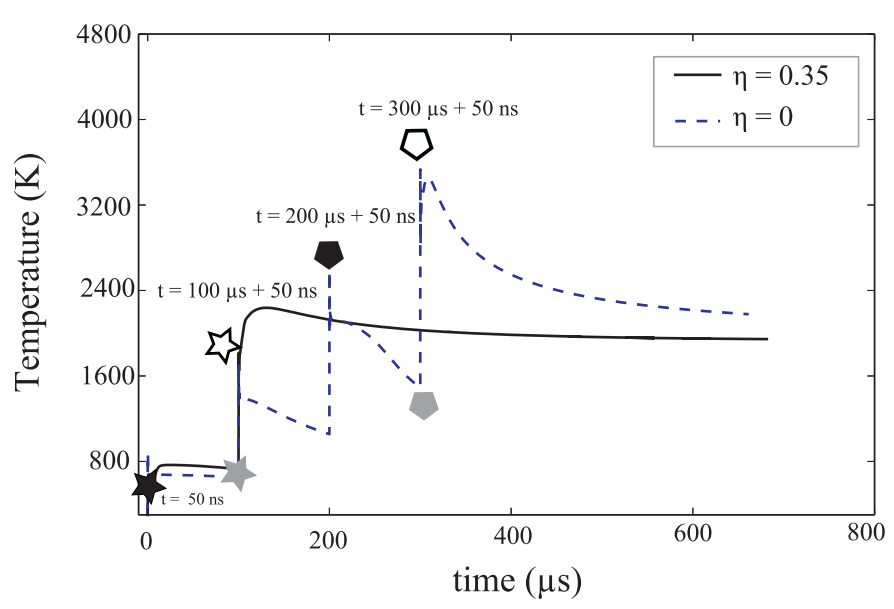

Fig. 10. Temporal evolution of the maximum value of gas temperature. Mixture ignites after two discharges if $\eta=0.35$ (solid line) whereas four discharges are needed if $\eta=0$ (dashed line).

\subsection{NRP discharges in methane-air mixture - quiescent flow conditions}

A sequence of NRP discharges characterized by the same pulse frequency, energy density and radius as the one used in NRP discharges in air simulations, are now applied to a methane-air mixture with an equivalence ratio $\phi=0.8$. The initial gas temperature of the quiescent flow is $T=300 \mathrm{~K}$. We retain a constant value of $\alpha=0.55$ whereas two values of the model parameter $\eta$ are analysed in order to study the impact of the early dissociation of $\mathrm{O}_{2}$ on mixture ignition.

Figure 10 shows the temporal evolution of the maximum gas temperature for $\eta=0$ and $\eta=0.35$ simulations. When $\mathrm{O}_{2}$ dissociation is considered in the simulations $(\eta=0.35)$ the mixture ignites after two discharge pulses. The gas temperature increases during the first discharge and, when the second discharge is applied, the temperature further increases following an asymptotic decrease towards the adiabatic flame temperature. When $\mathrm{O}_{2}$ dissociation induced by the plasma discharge is not considered in the simulations $(\eta=0)$, the mixture ignition is significantly delayed. Four discharge pulses are needed to ignite the mixture along with 

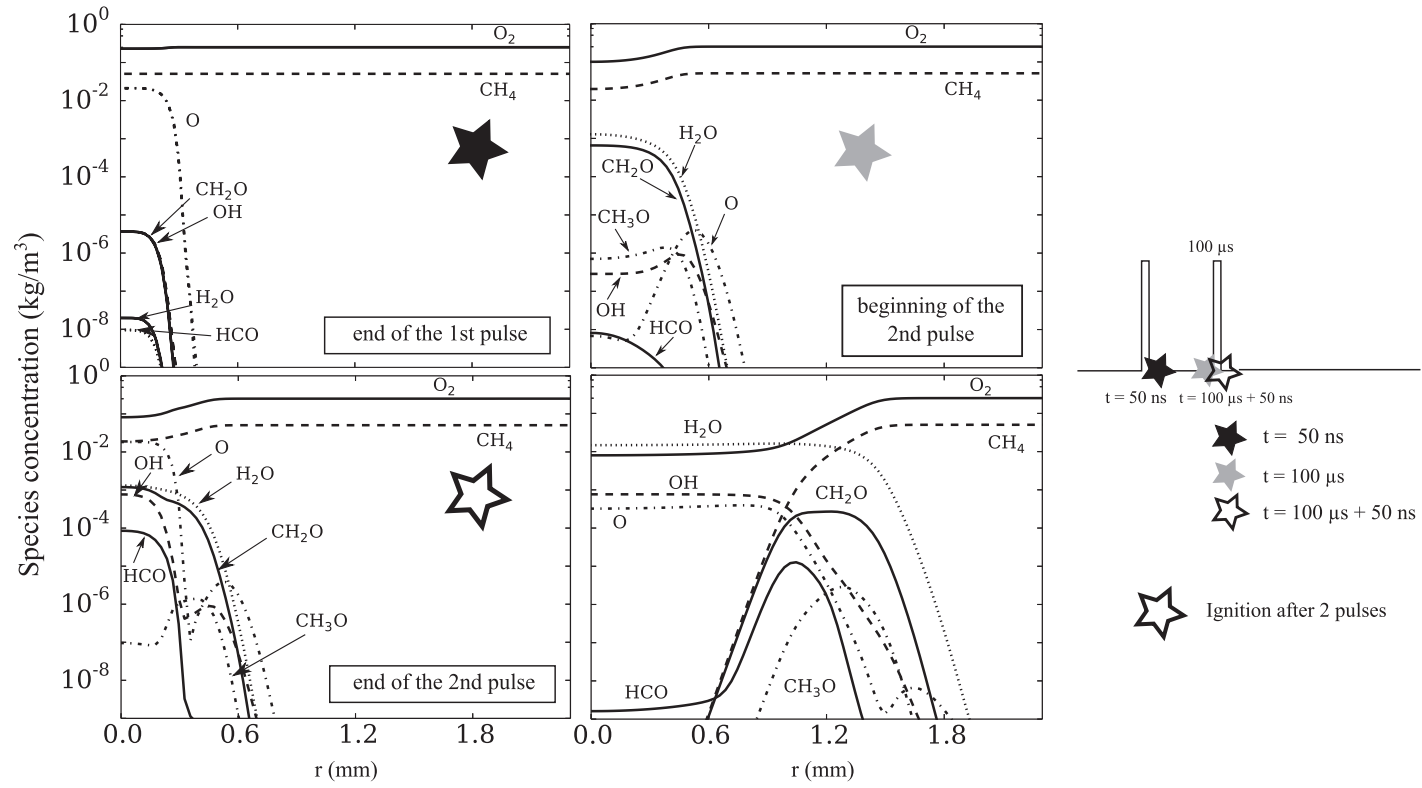

(a) $\eta=0.35$; with $\mathrm{O}_{2}$ dissociation model
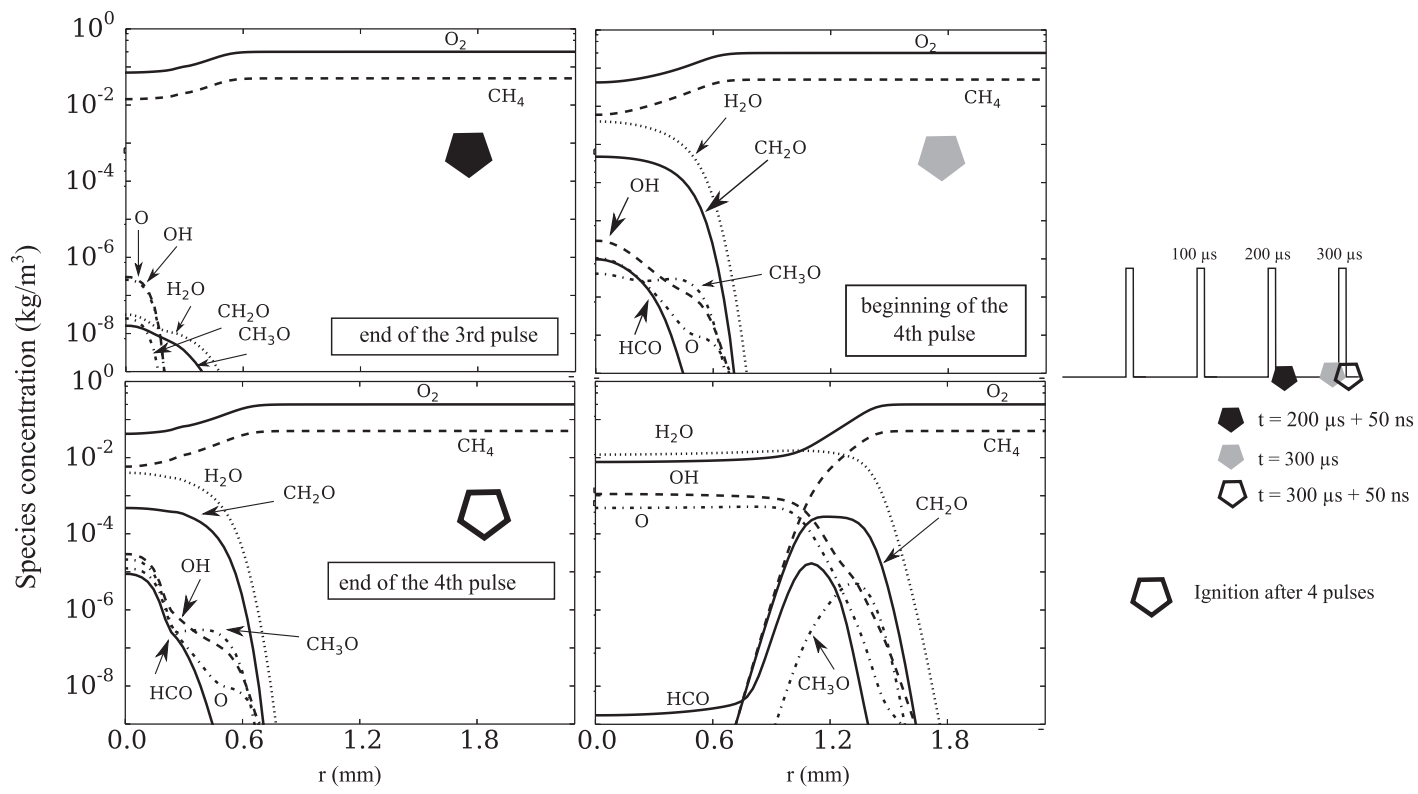

(b) $\eta=0$; without $\mathrm{O}_{2}$ dissociation model

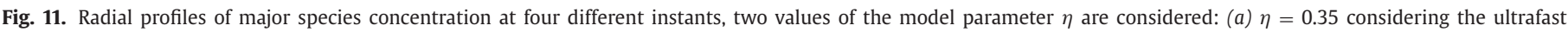
$\mathrm{O}_{2}$ dissociation model and (b) $\eta=0$ not considering the dissociation model.

higher values of the gas temperature compared to the case with dissociation. It is also interesting to note that for $\eta=0$ the gas temperature drops much rapidly after each pulse compared to the case $\eta=0.35$. This is explained by the higher gas expansion and acoustic energy runaway from the discharge zone as discussed in NRP discharges in air simulations. Nevertheless, Fig. 10 shows that the value of the gas temperature at $t=100 \mu \mathrm{s}$ is similar in both cases, its difference does not explain the ignition failure in the case of $\eta=0$. To further understand this phenomenon, Figs. 11a and b show the species concentration around the discharge zone at 4 different time instants, for $\eta=0.35$ and $\eta=0$. When $\mathrm{O}_{2}$ dissociation induced by the plasma is considered, Fig. 11a shows that, at the end of the first pulse, in addition to $\mathrm{O}$ radicals, small quantities of $\mathrm{OH}, \mathrm{CH}_{2} \mathrm{O}, \mathrm{HCO}, \mathrm{H}_{2} \mathrm{O}$ and other intermediate combustion species are also formed inside the discharge zone. This means that within $\tau_{\text {pulse }}$, a few $\mathrm{O}$ radicals oxidize $\mathrm{CH}_{4}$, initiating chain-branching reactions. Even though in small quantities, during the pulse interval, these species and the $\mathrm{O}$ radicals react to form $\mathrm{CO}_{2}$ and $\mathrm{H}_{2} \mathrm{O}$ and other intermediate combustion species, thus increasing the chemical reactivity of the mixture by the next pulse. By the time of the second discharge at $t=100 \mu \mathrm{s}$, the centre of the discharge channel is no longer a pure methane-air mixture but rather a pool of radicals and molecules that have been enhanced by the former discharge pulse. Indeed, the concentrations of $\mathrm{CH}_{2} \mathrm{O}, \mathrm{CH}_{3} \mathrm{O}$ and $\mathrm{HCO}$ are higher compared to the end of the first pulse whereas the concentrations of $\mathrm{O}$ and $\mathrm{OH}$ radicals are lower due to their reactions with intermediate species. Regarding $\mathrm{CH}_{4}$, combustion has barely started by the second discharge and it is only after the second 
Temperature fields
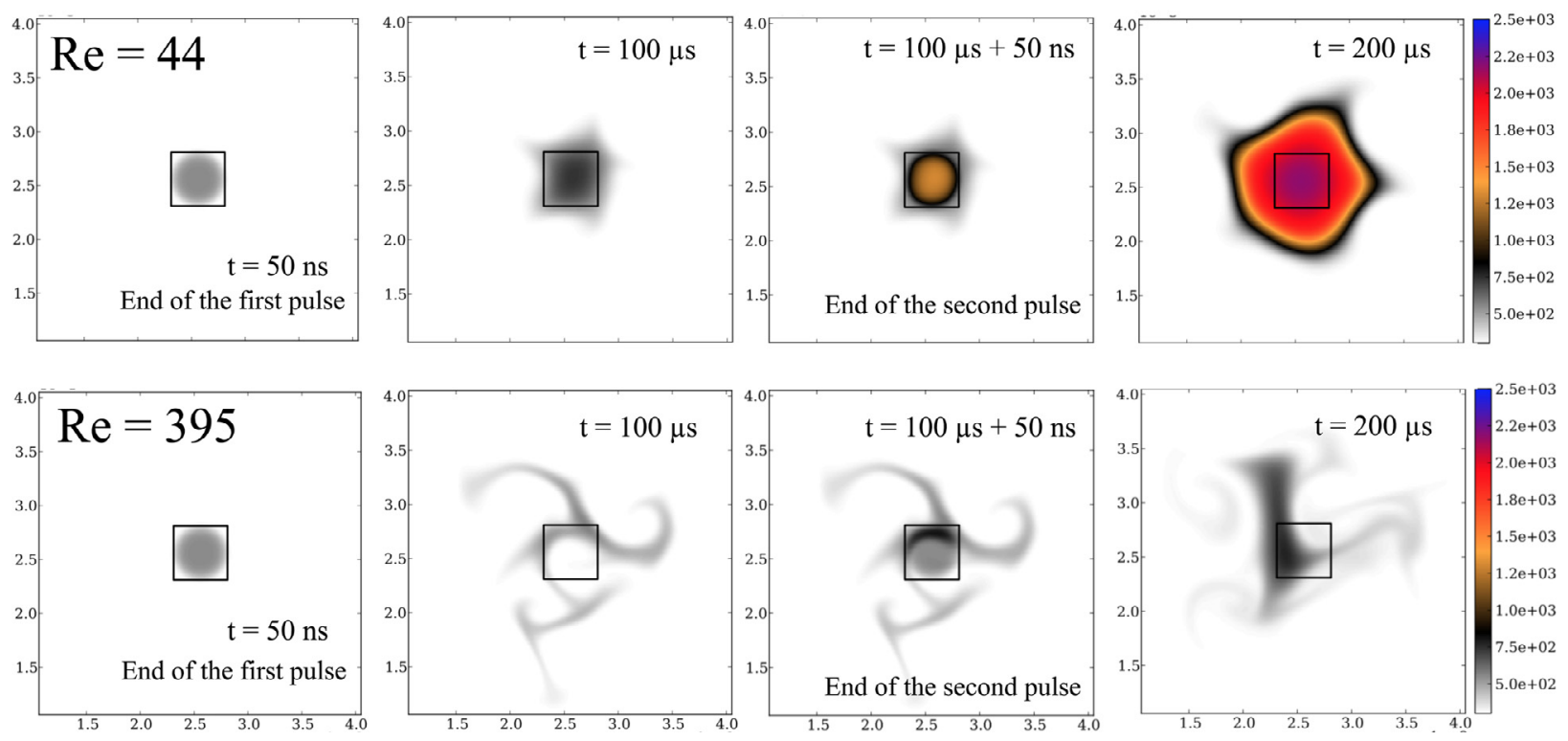

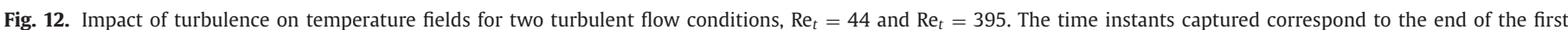

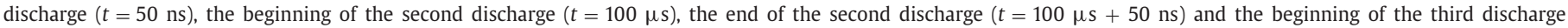
$(t=200 \mu \mathrm{s})$.

pulse that the concentration of $\mathrm{CH}_{4}$ decreases significantly indicating an effective ignition event. When $\mathrm{O}_{2}$ dissociation is not considered $(\eta=0)$, Fig. 11b shows that despite the higher values of the gas temperature (see Fig. 10), intermediate combustion species only become significant after the 3rd pulse. Chain-branching reactions will only be triggered when the gas temperature rises up to $T \approx 2800 \mathrm{~K}$ at $t=200 \mu \mathrm{s}+\tau_{\text {pulse. }}$. The difference in the gas chemical composition at the beginning of the second pulse explains, therefore, the ignition failure and the ignition success in the simulations.

These simulation results show that $\mathrm{O}$ radicals play a major role in the ignition enhancement of low gas temperature mixtures and lead to a decrease of the ignition delay and of the external source of energy needed to ignite. Different ignition delays and ignition energies (number of discharge pulses) are obtained whether the $\mathrm{O}_{2}$ dissociation model is considered or not. If only the ultrafast temperature increase is considered in simulations, the ignition delay is much longer and the temperature threshold necessary to trigger combustion chain-branching reactions is much higher than when the plasma model is considered.

\subsection{Methane-air mixture ignition - turbulent flow conditions}

The same sequence of NRP discharges is now applied to the same methane-air mixture but under turbulent flow conditions. Two initial flow fields characterized by a turbulent Reynolds number of $\operatorname{Re}_{t}=44$ and $\operatorname{Re}_{t}=395$ are imposed in order to study the impact of turbulence on mixture ignition. The model parameters $\alpha=0.55$ and $\eta=0.35$ are kept constant in all simulations.

Figure 12 shows the evolution of the gas temperature field for $\mathrm{Re}_{t}=44$ and $\mathrm{Re}_{t}=395$ simulations at the end of the first discharge $(t=50 \mathrm{~ns})$, in the beginning and at the end of the second discharge $(t=100 \mu \mathrm{s}$ and $t=100 \mu \mathrm{s}+50 \mathrm{~ns})$ and at $t=200 \mu \mathrm{s}$. The results show that, although turbulence does not have an impact during the discharge time $(t=50 \mathrm{~ns})$, its impact on the temperature field between two consecutive discharges increases with $\mathrm{Re}_{t}$. In low turbulent Reynolds number, $\mathrm{Re}_{t}=44$, after the first discharge the temperature field is not much affected by the turbulence yielding a homogeneous hot spot formation during the sec- ond discharge $\left(t=100 \mu \mathrm{s}+\tau_{\text {pulse }}\right)$. The evolutions of the maximum gas temperature and of the species concentration inside the discharge zone are close to those observed in Figs. 10 and $11 \mathrm{a}$, respectively and, therefore, the mixture ignites also after two pulses as in quiescent case. In higher turbulent Reynolds number, $\operatorname{Re}_{t}=395$, Fig. 12 shows that the hot spot created during the first discharge is convected and engulfed by the surrounding fresh gases due to the turbulence. By the time of the second pulse at $t=100 \mu \mathrm{s}$, the thermodynamic and chemical conditions inside the discharge zone are not homogeneous anymore and, in some locations of the discharge zone they are even similar to the thermochemical conditions found in the previous pulse. Therefore, the cumulative effect of the repetitively pulsed regime on mixture ignition, observed in quiescent flow simulations, is less effective. Figures 13a and b also show the impact of turbulence on the evolution of the $\mathrm{CH}_{2} \mathrm{O}$ mass density and vibrational energy density at the beginning and immediately after three discharge pulses. Although some species such as $\mathrm{O}$ and $\mathrm{OH}$ radicals still recombine quickly within two consecutive discharges, the results show that $\mathrm{CH}_{2} \mathrm{O}$ is being accumulated and spread around the discharge zone. The vibrational energy is also transported by the turbulence towards regions where the gas temperature and the $\mathrm{O}$ radicals concentration are too low to induce its relaxation into gas heating and, therefore, its contribution to the mixture ignition becomes less important. All these turbulence effects lead to an increase of the number of pulses needed to ignite the mixture. In this simulation $\left(\operatorname{Re}_{t}=395\right)$, characterized by a given initial distribution of the velocity field, four discharge pulses are needed to ignite the mixture. However, this number may vary for different turbulent events.

To mimic the chaotic nature of the turbulence and to better understand the phenomena occurring in turbulent conditions, four distinct turbulent events are simulated. Each turbulent event is characterized by a given spatial distribution of the turbulent eddies relative to the discharge zone, while the same Reynolds number, $\operatorname{Re}_{t}=395$ is retained. Figures $14 \mathrm{a}-\mathrm{d}$ show the results of each of these four simulations. The temporal evolution of three different temperatures are compared:

- maximum value of the gas temperature in the domain (not fixed in space); 


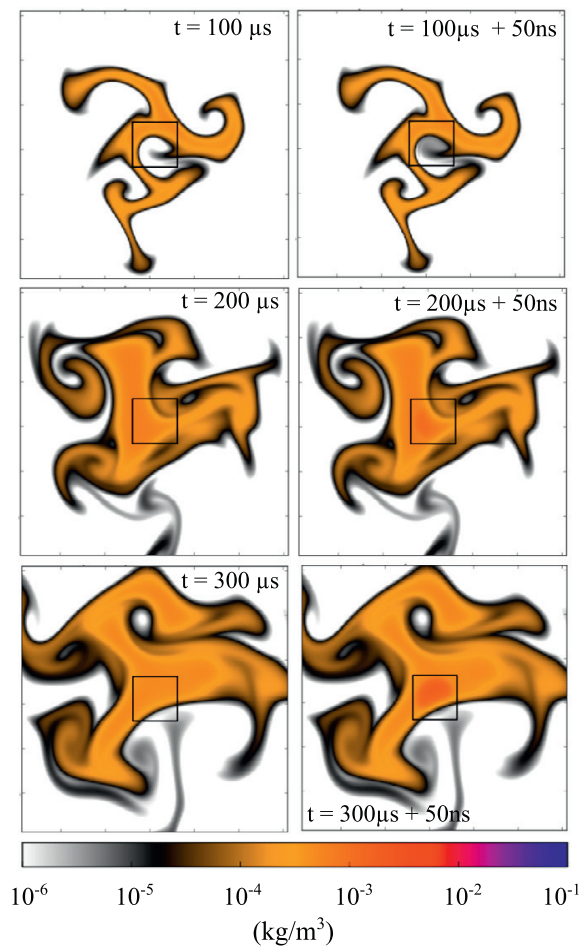

(a) $\mathrm{CH}_{2} \mathrm{O}$ mass density

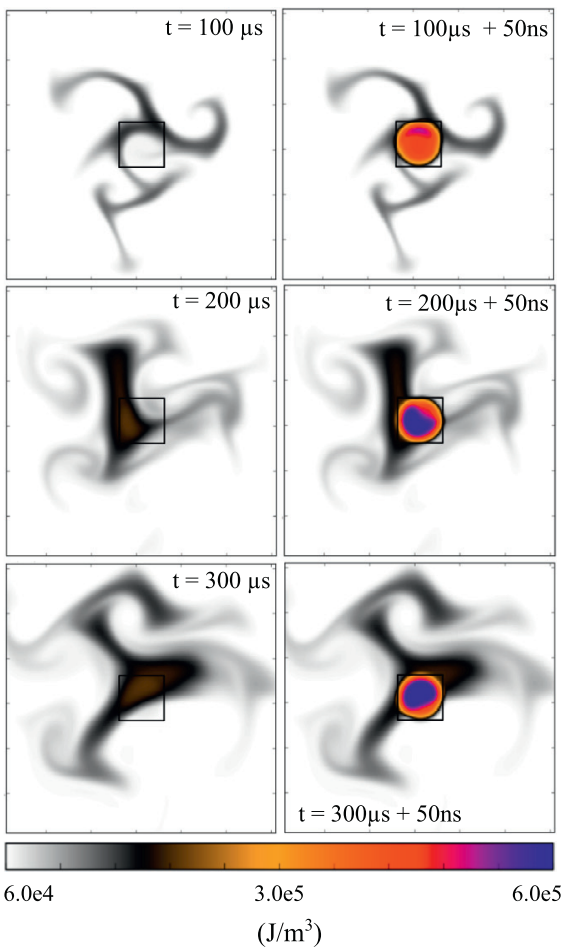

(b) Vibrational energy density

Fig. 13. Impact of turbulence on $\mathrm{CH}_{2} \mathrm{O}$ mass and gas vibrational energy density by the beginning and by the end of three consecutive discharges.

- the gas temperature at the centre of the discharge channel (fixed in space);

- maximum value of the gas temperature in quiescent flow conditions (fixed in space).

The results presented in Figs. 14a and b show that the mixtures ignite with 4 discharges whereas in Fig. $14 \mathrm{c}$ and d mixtures ignite with 3 discharges. In all simulations, within $t=0-100 \mu \mathrm{s}$, the maximum gas temperature in the domain is not much different from the one in quiescent flow simulations, thus showing a minor impact of the diffusion within the pulse interval $\Delta t=100 \mu \mathrm{s}$. Yet, the gas temperature at the centre of the discharge channel drops significantly within the timespan $t=0-100 \mu \mathrm{s}$ in Fig. 14a-c (see the timespan identified by 1 ). This means that, between the first and the second pulse, the hot spot is convected away from the discharge zone and consequently, the gas temperature at the centre of the discharge channel becomes close to the fresh gases temperature at the moment of the second discharge. In the timespan identified by 2 in Figs. 14a-c the gas temperature at the centre of the discharge increases again in two steps. The first step, occurs within the pulse and is related to the heat released by the discharge itself, whereas the second step within $t \approx 101-120 \mu \mathrm{s}$ is explained by the turnover of the high-temperature hot spots (that were convected around the discharge zone during the first discharge) from outside in the discharge zone and mostly by enhancement of exothermal reactions at the centre of the discharge zone. Indeed, the maximum value of the gas temperature in the domain matches the one at the centre of the discharge at $t \approx 120 \mu \mathrm{s}$.

Finally, the results presented in Fig. 14d show that the mixture does not ignite after the second pulse even though the value of the gas temperature at the centre of the discharge is close to the one of the quiescent flow simulations at $t=100 \mu \mathrm{s}$. As discussed in the quiescent case, radicals concentration play a major role on mixture ignition and although $\mathrm{O}$ and $\mathrm{OH}$ species react quickly be- tween pulses, $\mathrm{CH}_{2} \mathrm{O}$ (see Fig. 13a), $\mathrm{CO}$ and $\mathrm{CO}_{2}$ accumulate and spread around the discharge zone, therefore their local concentration inside the discharge zone is lower than the one observed in quiescent flow simulations. We also emphasize that computations are conducted with Le $\neq 1$ conditions and therefore the heat and species diffusivities are not the same. Indeed, the $\mathrm{CH}_{2} \mathrm{O}$ concentration is higher in the quiescent simulations even though the temperature values are similar in both cases. Regarding the results, mixture ignition always occurs before gas expansion characteristic time, $\tau \approx 0.25 \mu \mathrm{s}$ (discussed in NRP discharges in air simulations) and, therefore, if the local ignition delay time $\tau_{\text {ig }}$ computed with the local gas temperature and chemical composition at the end of the discharge pulse does not fulfill the criteria $\tau_{\text {ig }}<0.25 \mu \mathrm{s}$, the gas will first expand, leading to a temperature drop inside the discharge zone and therefore the mixture does not ignite. These small variations of the thermochemical conditions inside the discharge zone compared to the quiescent case might be a possible explanation for the ignition failure in Fig. $14 \mathrm{~d}$ at $t=100 \mu \mathrm{s}$. Another possible explanation is the thinner spatial extent of these favourable thermodynamic conditions compared to the quiescent flow case. While in quiescent flow conditions the hot spot conserves its spatial round-form, in turbulent flows the hot spot can be stretched into a narrowed heated zone while still keeping the same gas temperature and species concentration found in quiescent flow simulations. In a narrowed heated zone, assuming that the ignition delay criteria is fulfill $\tau_{i g}<0.25 \mu \mathrm{s}$ and a first ignition event occurs, the diffusive effects can be more or as important as the heat release rate of initial exothermal combustion reactions and, in this case, ignition fails.

After a successful ignition event, an initial kernel is formed and either develops into a sustainable flame kernel or extinguishes. The decrease of the gas temperature in the centre of the discharge channel observed in Figs. $14 \mathrm{c}$ and d after a successful kernel formation (see the timespan identified by 3 ) shows the 


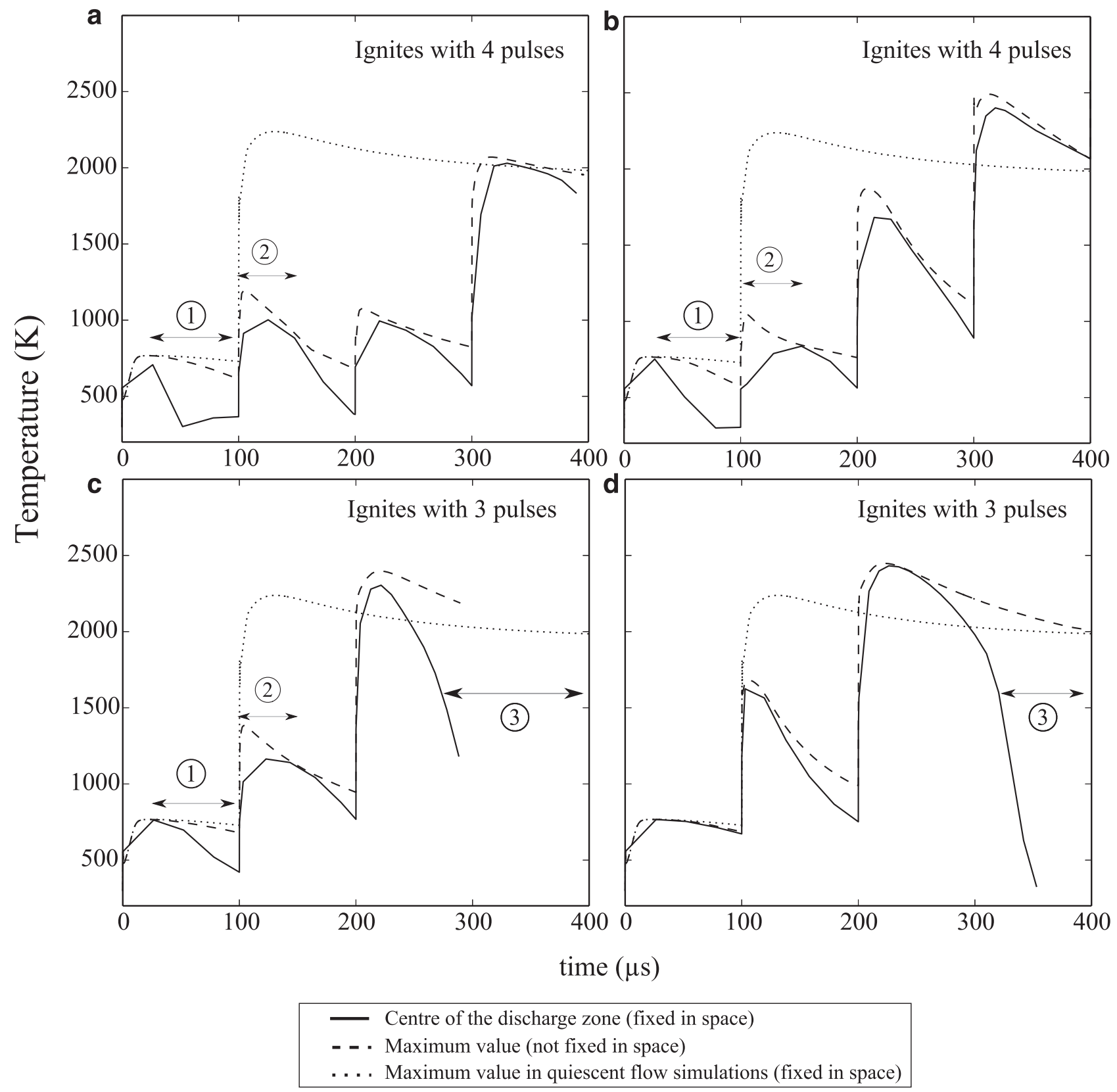

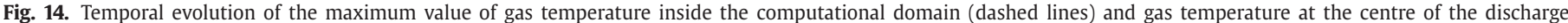
zone (solid lines) in four different initial conditions of the velocity field. Results are compared to quiescent flow condition (dotted lines).

impact of the turbulence on the convection of these initial flame kernels.

\section{Conclusions}

The application of non-equilibrium plasmas to lean premixed or partial premixed combustion regimes can provide additional ways to control mixture ignition and extend flame stability domains. In particular, non-equilibrium plasmas produced by Nanosecond Repetitively Pulsed (NRP) discharges are an energy-efficient way to generate 0 radicals, even at low gas temperatures, which enhances combustion processes.

Conventional ignition models, based on the assumption of thermal equilibrium, cannot capture this low-temperature generation of radicals and, therefore, additional thermal non-equilibrium processes have to be considered. Although several detailed plasma ki- netic models have been proposed in the literature [19,21,29,30,38$42]$ to capture these non-equilibrium processes, they require prohibitive computational resources in DNS studies at high Reynolds number. The model developed in the present paper is a high level model of plasma-assisted ignition that captures the governing plasma phenomena without having to incorporate detailed non-equilibrium plasma kinetics, thus reducing the computational costs of high Reynolds number flows DNS computations. Multi-dimensional DNS computations of plasma-assisted ignition by repetitively pulsed discharges can then be performed to focus on understanding plasma/combustion/turbulence interactions.

In Nanosecond Repetitively Pulsed (NRP) discharges at atmospheric pressure, about $90 \%$ of the discharge energy is stored into electronic and vibrational states of $\mathrm{N}_{2}$ molecules. Dissociative quenching reactions between ground state molecules and electronically excited $\mathrm{N}_{2}$ molecules lead to an ultrafast increase of the 
gas temperature and to the dissociation of species, which impacts mixture ignition delay. The relaxation of vibrationally excited $\mathrm{N}_{2}$ molecules takes longer and is associated to a much slower heat release. Based on these phenomenological characteristics, in the present model, the discharge energy is decomposed into (1) ultrafast chemical and heat energy deposition with a characteristic time $\tau_{\text {pulse }}$; and (2) slow heat energy deposition with a characteristic time $\tau_{V T}$. In the model closure formulation, two parameters are defined:

- $\alpha$ : the fraction of the discharge energy that leads to ultrafast heating and $\mathrm{O}_{2}$ dissociation within $\tau_{\text {pulse }}=50 \mathrm{~ns}$

- $\eta$ : the fraction of the discharge energy leading to $\mathrm{O}_{2}$ dissociation within $\tau_{\text {pulse }}=50 \mathrm{~ns}$.

The main conclusions of the simulations performed in this work are summarized as follows:

- The ultrafast energy deposition within $\tau_{\text {pulse }}=50$ ns occurs as a nearly constant volume process. The ultrafast temperature increase is accompanied by an increase of the gas pressure inside the discharge zone leading to gas expansion and shock waves formation at each discharge pulse. In this process only the discharge energy going into ultrafast gas heating contribute to the acoustic energy runaway from the centre of the discharge channel.

- The early dissociation of the $\mathrm{O}_{2}$ molecules induced by the plasma discharge plays a major role on the ignition enhancement of low temperature mixtures. It decreases the delay and the external energy needed to ignite. Different ignition delays and ignition energies (number of discharge pulses) are obtained whether the $\mathrm{O}_{2}$ dissociation model is considered or not. If only the ultrafast temperature increase is considered in simulations, the ignition delay increases.

- Simulation results of plasma-assisted ignition in turbulent flows show that turbulence impacts the transient ignition phenomena. Between two consecutive discharges, the radicals enhanced by the previous pulse are convected away from the discharge zone, which leads to a local decrease of their concentration, therefore minimizing the cumulative effect of repetitively pulsed discharges. Furthermore, for a given turbulent Reynolds number, the initial spatial distribution of the turbulent eddies relative to the discharge zone, may also stretch the hightemperature and highly-reactive zone so that diffusion effects will also impact the mixture ignition.

The simulations results of the present work show that ignition by NRP discharges is influenced by turbulence and that non-equilibrium effects should be considered in the simulation of plasma-assisted ignition in order to capture the fast production of radicals at low gas temperatures. This is particularly critical for simulations of plasma-assisted ignition in high Reynolds number flows.

\section{Acknowledgments}

This research has been supported by Agence Nationale de la Recherche, FAMAC project (grant no. ANR-12-VPTT-0002) and PLASMAFLAME project (grant no. ANR-11-BS09-0025). This work was performed using HPC resources from GENCI-IDRIS (grant no. 2015-2b0164).

\section{References}

[1] S. Barbosa, G. Pilla, D.A. Lacoste, P. Scouflaire, S. Ducruix, C.O. Laux, D. Veynante, Influence of nanosecond repetitively pulsed discharges on the stability of a swirled propane/air burner representative of an aeronautical combustor, Phil. Trans. R. Soc. A 373 (2015) 20140335.
[2] G. Pilla, D. Galley, D.A. Lacoste, F. Lacas, D. Veynante, C. Laux, Plasma-enhanced combustion of a lean premixed air-propane turbulent flame using a repetitively pulsed nanosecond discharge, IEEE Trans. Plasma Sci. 34 (6) (2006) 2471-2477.

[3] W. Kim, H. Do, M.G. Mungal, M.A. Cappelli, A study of plasma-stabilized diffusion flames at elevated ambient temperatures, Combust. Flame 153 (4) (2008) 603-615.

[4] I.V. Adamovich, I. Choi, N. Jiang, J.-H. Kim, S. Keshav, W.R. Lempert, E. Mintusov, M. Nishihara, M. Samimy, M. Uddi, Plasma assisted ignition and high-speed flow control: non-thermal and thermal effects, Plasma Sources Sci. Technol. 18 (3) (2009) 034018.

[5] T. Ombrello, S.H. Won, Y. Ju, S. Williams, Flame propagation enhancement by plasma excitation of oxygen. Part I: effects of $\mathrm{O}_{3}$, Combust. Flame 157 (2010) 1906-1915.

[6] W. Sun, M. Uddi, T. Ombrello, S.H. Won, C. Carter, Y. Ju, Effects of nonequilibrium plasma discharge on counterflow diffusion flame extinction, Proc. Combust. Inst. 33 (2011) 3211-3218.

[7] A. Starikovskiy, N. Aleksandrov, Plasma-assisted ignition and combustion, Prog. Energy Combust. Sci. 39 (1) (2013) 61-110.

[8] S. Macheret, M. Shneider, R. Miles, Energy efficiency of plasma-assisted combustion in Ram/Scramjet engines, 36th AIAA Plasmadynamics and Lasers Conference, Toronto, Ontario, Canada, (2005). paper AIAA 2005-5371.

[9] Y. Ju, W. Sun, Plasma assisted combustion: dynamics and chemistry, Prog. Energy Sci. Combust. 48 (2015) 21-83.

[10] I. Kimura, H. Aoki, M. Kato, The use of a plasma jet for flame stabilization and promotion of combustion in supersonic air flows, Combust. Flame 42 (1981) 297-305.

[11] S.B. Leonov, D.A. Yarantsev, Plasma-induced ignition and plasma-assisted combustion in high-speed flow, Plasma Sources Sci. Technol. 16 (2007) 132-138.

[12] K. Criner, A. Cessou, J. Louiche, P. Vervisch, Stabilization of turbulent lifted jet flames assisted by pulsed high voltage discharge, Combust. Flame 144 (2006) 422-425.

[13] S.B. Leonov, I.V. Kochetov, A.P. Napartovich, V.A. Sabelnikov, D. Yarantsev, Plasma-induced ethylene ignition and flameholding in confined supersonic air flow at low temperatures, IEEE Trans. Plasma Sci. 39 (2011) 781-787.

[14] W.L. Nighan, Electron energy distributions and collision rates in electrically excited $\mathrm{N}_{2}$, CO and $\mathrm{CO}_{2}$, Phys. Rev. A 2 (1970) 1989-2000.

[15] N.L. Aleksandrov, F.I. Vysikailo, R.S. Islamov, I.V. Kochetov, A.P. Napartovich V.G. Pevgov, Electron distribution function in 4:1 $\mathrm{N}_{2}-\mathrm{O}_{2}$ mixture, Teplofiz. Vys Temp. 19 (1) (1981) 22-27.

[16] G.D. Stancu, F. Kaddouri, D.A. Lacoste, C.O. Laux, Atmospheric pressure plasma diagnostics by OES, CRDS and TALIF, J. Phys. D: Appl. Phys. 43 (2010) 124002.

[17] A. Flitti, S. Pancheshnyi, Gas heating in fast pulsed discharges in $\mathrm{N}_{2}-\mathrm{O}_{2}$ mixtures, Eur. Phys. J. 45 (2009) 21001

[18] A. Lo, G. Cleon, P. Vervisch, A. Cessou, Spontaneous raman scattering: a useful tool for investigating the afterglow of nanosecond scale discharges in air, Appl. Phys. B 107 (2012) 229-242.

[19] N. Popov, Investigation of the mechanism for rapid heating of nitrogen and air in gas discharges, Plasma Phys. Rep. 27 (10) (2001) 886-896.

[20] N.L. Aleksandrov, S.V. Kindysheva, M.M. Nudnov, A.Y. Starikovskiy, Mechanism of ultra-fast heating in a non-equilibrium weakly ionized air discharge plasma in high electric fields, J. Phys. D: Appl. Phys. 43 (2010) 255201.

[21] N.A. Popov, Fast gas heating in a nitrogenoxygen discharge plasma. I. Kinetic mechanism, J. Phys. D: Appl. Phys. 44 (2011) 285201.

[22] D.L. Rusterholtz, D.A. Lacoste, G.D. Stancu, D.Z. Pai, C.O. Laux, Ultrafast heating and oxygen dissociation in atmospheric pressure air by nanosecond repetitively pulsed discharges, J. Phys. D: Appl. Phys. 46 (2013) 464010.

[23] Z. Yin, I. Adamovich, W. Lempert, Measurements of temperature and hydroxyl radical generation/decay in lean fuel-air mixtures excited by a repetitively pulsed nanosecond discharge, Proc. Combust. Inst. 34 (2) (2013) 3249-3258.

[24] D. Breden, L.L. Raja, C.A. Idicheria, P.M. Najt, S. Mahadevan, A numerical study of high-pressure non-equilibrium streamers for combustion ignition application, J. Appl. Phys. 114 (2013) 083302.

[25] S.V. Pancheshnyi, D.A. Lacoste, A. Bourdon, C.O. Laux, Ignition of propaneair mixtures by a repetitively pulsed nanosecond discharge, IEEE Trans. Plasma Sci. 34 (6) (2006) 2478-2487.

[26] W. Sun, M. Uddi, S.H. Won, T. Ombrello, C. Carter, Y. Ju, Kinetic effects of nonequilibrium plasma-assisted methane oxidation on diffusion flame extinction limits, Combust. Flame 159 (1) (2012) 221-229.

[27] I.N. Kosarev, V.I. Khorunzhenko, E.I. Mintoussov, P.N. Sagulenko, N.A. Popov, S.M. Starikovskaia, A nanosecond surface dielectric barrier discharge at elevated pressures: time-resolved electric field and efficiency of initiation of combustion, Plasma Sources Sci. Technol. 21 (2012) 045012.

[28] M.S. Bak, H. Do, M.G. Mungal, M.A. Cappelli, Plasma-assisted stabilization of laminar premixed methane/air flames around the lean flammability limit, Combust. Flame 159 (10) (2012) 3128-3137.

[29] J.K. Lefkowitz, P. Guo, A. Rousso, Y. Ju, Species and temperature measurements of methane oxidation in a nanosecond repetitively pulsed discharge, Phil. Trans. Ser. A: Math. Phys. Eng. Sci. 373 (2015) 20140333.

[30] A.M. Starik, B.I. Loukhovitski, A.S. Sharipov, N.S. Titova, Physics and chemistry of the influence of excited molecules on combustion enhancement, Phil. Trans. R. Soc. A 373 (2015) 20140341

[31] M. Thiele, J. Warnatz, U. Maas, Geometrical study of spark ignition in two dimensions, Combust. Theory Model. 4 (4) (2000) 413-434

[32] M. Thiele, S. Selle, U. Riedel, J. Warnatz, U. Maas, Numerical simulation of spark ignition including ionization, Proc. Combust. Inst. 28 (2000) 1177-1185. 
[33] S. Nakaya, K. Hatori, M. Tsue, M. Kono, D. Segawa, T. Kadota, Numerical analysis on flame kernel in spark ignition methane/air mixtures, J. Propul. Power 27 (2) (2011) 132-138.

[34] N. Chakraborty, E. Mastorakos, R.S. Cant, Effects of turbulence on spark ignition in inhomogeneous mixtures: a direct numerical simulation (DNS) study, Combust. Sci. Technol. 179 (1-2) (2007) 293-317.

[35] F. Tholin, D.A. Lacoste, A. Bourdon, Influence of fast-heating processes and o atom production by a nanosecond spark discharge on the ignition of a lean $\mathrm{H}_{2}$ /air premixed flame, Combust. Flame 161 (2014) 1235-1246.

[36] T. Poinsot, D. Veynante, Theoretical and numerical combustion, R. T. Edwards, Inc., 2011.

[37] A. Coussement, O. Gicquel, J. Caudal, B. Fiorina, G. Degrez, Three-dimensional boundary conditions for numerical simulations of reactive compressible flows with complex thermochemistry, J. Comput. Phys. 231 (17) (2012) 5571-5611.

[38] N.A. Popov, Kinetic processes initiated by a nanosecond high-current discharge in hot air, Plasma Phys. Rep. 37 (9) (2011) 807-815.

[39] N.L. Aleksandrov, S.V. Kindysheva1, I.V. Kochetov, Kinetics of low-temperature plasmas for plasma-assisted combustion and aerodynamics, Plasma Sources Sci. Technol. 23 (1) (2014) 015017.

[40] D. Burnette, A. Montello, I.V. Adamovich, W.R. Lempert, Nitric oxide kinetics in the afterglow of a diffuse plasma filament, Plasma Sources Sci. Technol. 23 (2014) 045007.

[41] I. Shkurenkov, D. Burnette, W.R. Lempert, I.V. Adamovich, Kinetics of excited states and radicals in a nanosecond pulse discharge and afterglow in nitrogen and air, Plasma Sources Sci. Technol. 23 (2014) 065003.
[42] I.V. Adamovich, T. Li, W.R. Lempert, Kinetic mechanism of molecular energy transfer and chemical reactions in low-temperature air-fuel plasmas, Phil. Trans. R. Soc. A 373 (2015) 20140336.

[43] R.C. Millikan, D.R. White, Systematics of vibrational relaxation, J. Chem. Phys. 39 (1963) 3209-3213.

[44] N.A. Popov, Fast gas heating initiated by pulsed nanosecond discharge in atmospheric pressure air, AIAA Aerospace Sciences Meeting, Grapevine, TX, 7-10 January, 2013. paper 2013-105251.

[45] C. Vasquez-Espí, A. Liñan, Fast, non-diffusive ignition of a gaseous reacting mixture subject to a point energy source, Combust. Theory Model. (2001) 485498.

[46] A.W. Cook, W.H. Cabot, A high-wavenumber viscosity for high-resolution numerical methods, J. Comput. Phys. 195 (2004) 594-601.

[47] A.W. Cook, W.H. Cabot, Hyperviscosity for shock-turbulence interactions, J. Comput. Phys. 203 (2005) 379-385.

[48] B. Fiorina, S.K. Lele, An artificial nonlinear diffusivity method for supersonic reacting flows with shocks, J. Comput. Phys. 222 (2007) 246-264

[49] P. Lindstedt, Modeling of the chemical complexities of flames, Symp. (Int.) Combust. 1 (27) (1998) 269-285.

[50] D.A. Xu, D.A. Lacoste, D.L. Rusterholtz, P.Q. Elias, G.D. Stancu, Experimental study of the hydrodynamic expansion following a nanosecond repetitively pulsed discharge in air, Appl. Phys. Lett. 99 (2011) 121502. 